\title{
AN EXPERIMENTAL STUDY OF INTESTINAL OBSTRUCTION *
}

\author{
JOHN A. HARTWELL, M.D., J. P. HOGUET, M.D. \\ AND \\ FENWICK BEEKMAN, M.D. \\ NEW YOBK
}

Intestinal obstruction in man, if unrelieved, speedily causes death. The fatal outcome is too rapid to be the result of starvation, and three general theories have been advanced to explain it:

1. A disorder of the nervous mechanism controlling the cardiac and vasomotor systems.

2. A bacterial infection of the organism by the passage outward of bacteria from the intestinal lumen.

3. An intoxication from poisonous substances imprisoned in the intestine orally to the obstruction.

Two modifications of the last theory have recently come into prominence. The first was originally advanced by Vidal, ${ }^{1}$ and more recently elaborated by Maury Draper (formerly Draper Maury), in which the presence of a substance in the upper intestinal tract was believed to exist, which, unless neutralized by substances elaborated lower down, entered the system as a poison.

The second modification is advanced by Whipple, Stone and Bernheim. ${ }^{3}$ These workers believe that stagnation of the duodenal contents results in the formation of a severe poison, which readily enters the system, and produces death. This poison may be obtained from the mucosal cells of the duodenum as well as from the duodenal contents.

\section{THE THEORY OF A NERVOUS DISORDER}

In favor of this theory, clinical evidence has been adduced. The tachycardia, the low blood-pressure, the profound collapse of the patient,

* From the Department of Surgery of the Cornell University Medical College.

* Submitted for publication March 3, 1914.

* Preliminary reports on the work here detailed have appeared in Am. Jour. Med. Sc., March, 1912, p. 357; Jour. Am. Med. Assn., 1912, lix, 82; Jour. Exper. Med., 1913, xviii, No. 2, p. 139. These reports are freely abstracted in the present article in order to present the subject in its entirety.

1. Vilal: Rev. de chir., 1900, xxvi, 521 ; Cong. Frane. de chir., 1905, xxviii, 1237.

2. Draper, J. W.: Experimental Intestinal Obstruction, Jour. Am. Med. Assn., 1911, lvii, 1338; John Hopkins Hosp. Bull., 1909, xx, 184; Am. Jour. Med. Sc., 1909, cxxxvii, 725; Death in Acute Intestinal Obstruction and Kindred Conditions Is Due to Physiologic Disturbance, Jour. Am. Med. Assn., 1910, liv, 5.

3. Whipple, Stone and Bernheim: Jour. Exper. Med., 1913, xvii, No. 3, p. 286. 
and the wide dilatation of the splanchnic blood-vessels, all point to a loss of activity on the part of the medullary nerve-centers. The early writers saw in these the results of a reflex disturbance from stimuli acting on the nerve endings in the intestinal wall. It is undoubtedly true, however, that exactly this train of events may arise from a toxemia or a bacteriemia without the intervention of any afferent nerve impulses.

Recently, Braun and Boruttau 4 have modified this theory somewhat, and assign the above-described symptoms to a disturbance of the circulation resulting from interference, chiefly mechanical, with the inherent nerve plexuses in the intestinal wall. They see a parallel between a gradual bleeding to death and the death in intestinal obstruction. The loss of body fluids resulting from failure of absorption, the enormous outflow of fluid into the intestine, the persistent vomiting, and the stagnation of blood in the splanchnic area lead to an anemia of the brain-centers which progresses till these centers cease their activity, and death results. They experimented most exhaustively on rabbits to support this view, but the evidence is all indirect, and seems to us not to amount to a proof of the theory. We are unable to find in the literature any convincing experimental work that the nervous system is primarily at fault. Certainly, as death approaches, there is a profound disturbance of the nervous control of the heart, blood-vessels and respiration, but this, we believe, is in no sense a reflex disturbance, nor the result of an anemia, per se, of the nerve-centers. It differs in no way from the last stages of any severe sickness which is progressing toward a fatal issue. The loss of body fluids is a matter of the utmost importance, but not because of its effect in producing a brain anemia.

\section{THE THEORY OF BACTERIAL INFECTION}

The infection theory has much more to support it. The intesrinal lumen is the normal habitat of innumerable micro-organisms which are potentially pathogenic. When an obstruction exists, these no longer have their normal outlet per anum. They are dammed up in the intestine under favorable conditions for their growth $\left.(\mathbf{M c C l u r e})^{5}\right)$. The damage to the intestinal mucosa may allow their passage outward, either into the blood-stream, lymphatics, or directly into the peritoneal cavity. Proof of this possibility is seen clinically in the presence of a peritonitis as a complication of intestinal obstruction without perforation; also in the frequent finding of colon bacillus in the blood as a pathogenic micro-organism, under very varied conditions of intestinal disturbances less severe than an obstruction, and in the bacteriemia from the Bacillus typhosus when the intestine is ulcerated by the action of that organism.

4. Braun and Boruttau: Deutsch. Ztschr. f. Chir., 1908, xcvi, 544.

5. McClure, R. D.: An Experimental Study of Internal Obstruction, Jour. Am. Med. Assn., 1907, xlix, 1003. 
Von Khantz, ${ }^{6}$ experimenting on rabbits in a low intestinal obstruction, often found a bacterial invasion of the blood and the peritoneum, but never the former without the latter. Borszesky and von Genersich,? on the other hand, found a blood infection with no invasion of the peritoneum. There can be no doubt that a bacterial invasion of both the peritoneum and the blood may take place in intestinal obstruction, but it is not an essential accompaniment. It occurs late as a complication, often a terminal one. Both clinically and experimentally it will result most often when the obstruction is complicated by a strangulation. Without this complication, intestinal obstruction will kill with no passage of bacteria beyond the intestinal wall.

Tables 1 and 2 give the results of our experiments bearing on this point. In the first series the obstruction was produced by dividing the intestine from 10 to $30 \mathrm{~cm}$. below the pylorus, and closing the ends by inversion. It will be noted that in all these cases some micro-organisms were found in the organs examined. This, we believe, was due to the fact that all the examinations were made several hours post mortem, because all the animals died during the night, and possibly to a local soiling at the site of operation. In the second series, however, the obstruction was produced by the clamp described below, and the animals were either killed when it was believed they were too sick to live over night, and immediately examined, or examined very soon after death occurred from the obstruction itself. This series of seven cases furnishes irrefutable proof that death results from an obstruction of the upper intestine in the dog, without any invasion of the peritoneum, blood, iiver or spleen by bacteria, which are demonstrable by the methods employed. The methods in the two series were exactly similar and their efficiency in detecting organisms is amply demonstrated in the first. The cultures were taken at autopsy on slant agar or Loeffler bloodserum, or both. Usually four tubes, sometimes only three of each, were inoculated from each tissue, and grown under both aerobic and anaerobic conditions at incubator temperature. For the anaerobes the Buchner method or the Cornell modification of it was used. The tubes were examined at the end of one, two and three days. All the cultures were made in the sterile room of the Cornell bacteriology laboratory. This consists of a closed cabinet, ventilated through a bacteria-proof filter, in the roof of which is suspended an ordinary revolving lawn-sprinkler. The water is turned through this for fifteen or twenty minutes prior to taking the cultures. Thus the air is mechanically sterilized by i:ashing out the micro-organisms. All the needed apparatus for taking the cultures and smears is assembled before beginning the inoculations,

6. Von Khantz: Arch. f. klin. Chir., 1909, xxxviii, 412.

7. Borszesky and von Genersich: Beitr. z. klin. Chir., 1902, xxxvi, 448. 
and the air-tight door is kept closed until all cultures are completed. The technic in making the inoculations is that usually employed in obtaining cultures from post-mortem material. The efficiency of the room and the method is demonstrated by the fact that only three air contaminations were found in several hundred tubes.

In some of the later cases of the second series no cultures were taken from the spleen, since it was noted that this organ never showed infection when the liver and peritoneum were without infection. Often, too, the spleen cultures gave no growth when the other organs were actively infected. A summary of this series shows that the femoral blood was cultured seven times, and always was without growth; the liver was cultured six times, and showed one colony of Gram-positive cocci, in one tube of one case, probably an air contamination; the results from the peritoneal cultures were exactly the same as from the liver; the spleen was cultured only twice, with negative findings both times; the jejunal or duodenal contents above the clamp were cultured seven times, and all tubes showed an abundant growth of various microorganisms.

TABLE 1.-CULTURES FROM ORGANS OF ANIMALS WITH INTESTINAL OBSTRUCTIONS, SERIES 1

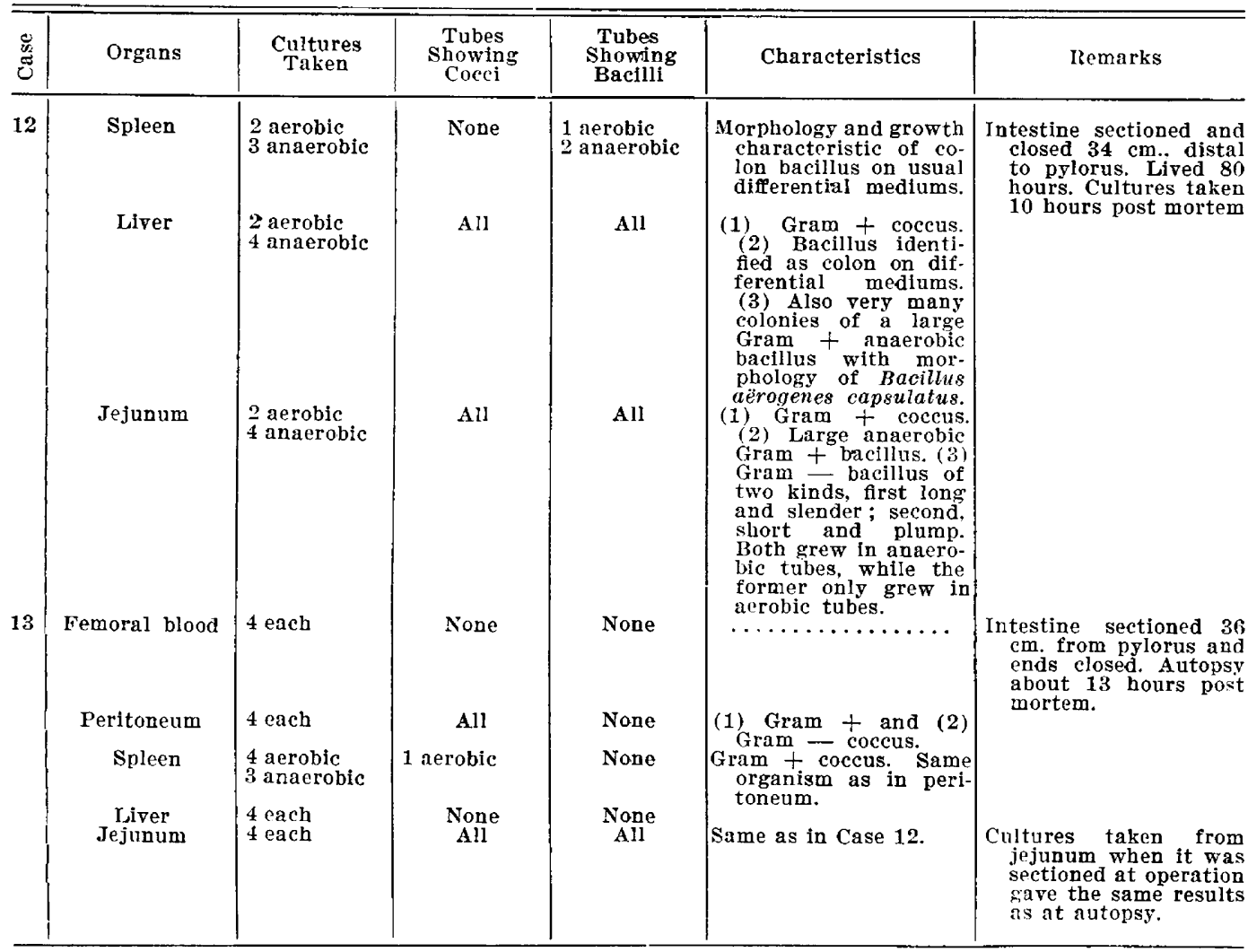


TABLE 1.-CONTINUED

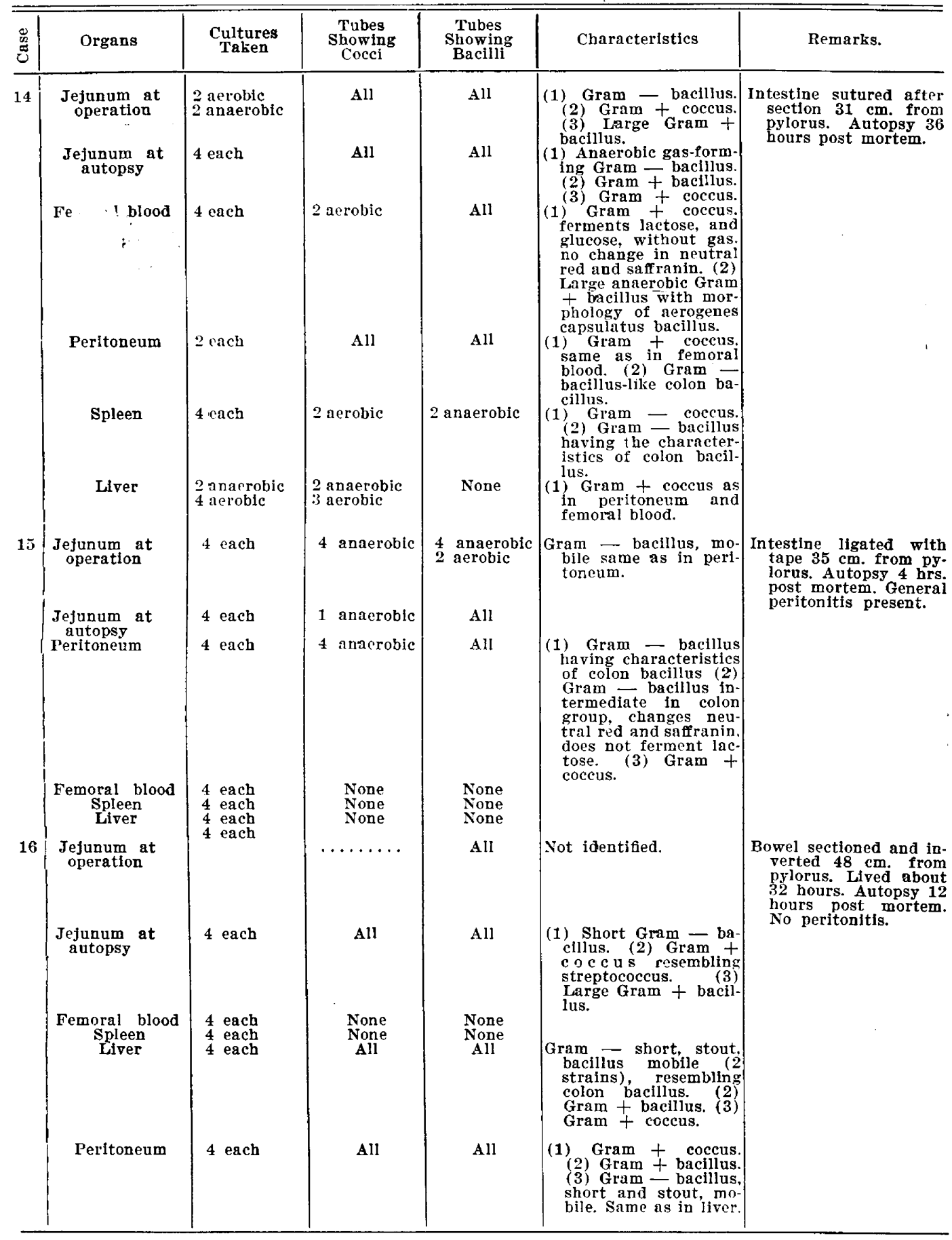


TABLE 1.-CONTINOED

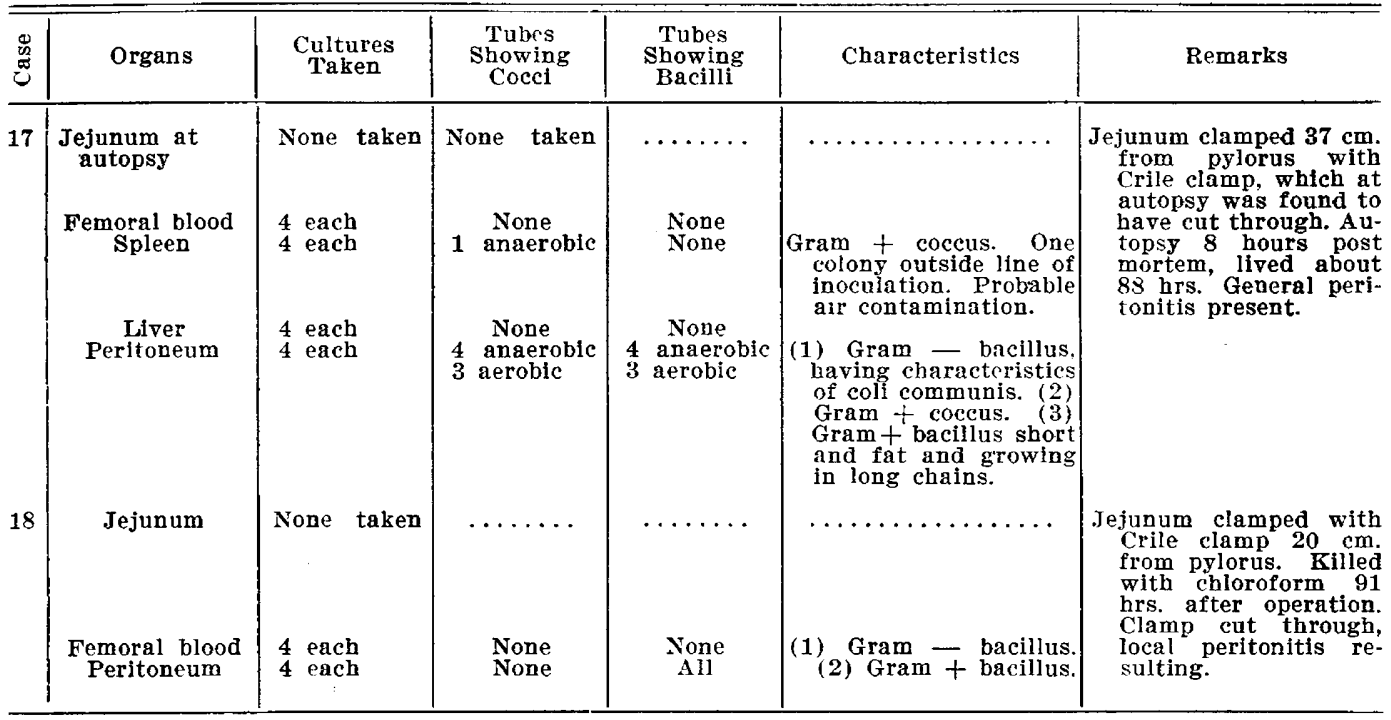

TABLE 2.-CULTURES FROM ORGANS OF ANIMALS WITH INTESTINAL OBSTRUCTIONS, SERIES 2

\begin{tabular}{|c|c|c|c|c|c|c|}
\hline 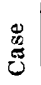 & Organs & $\begin{array}{l}\text { Cultures } \\
\text { Taken }\end{array}$ & $\begin{array}{c}\text { Tubes } \\
\text { Showing } \\
\text { Cocel }\end{array}$ & $\begin{array}{l}\text { Tubes } \\
\text { Showing } \\
\text { Bacilli }\end{array}$ & Characteristics & Remarks \\
\hline 19 & $\begin{array}{c}\text { Femoral blood } \\
\text { Spleen } \\
\text { Liver } \\
\text { Peritoneum } \\
\text { Abscess around } \\
\text { clamp }\end{array}$ & $\begin{array}{l}3 \text { aerobic } \\
3 \text { anaerobic } \\
\\
4 \text { aerobic } \\
3 \text { anaerobic } \\
4 \text { aerobic } \\
4 \text { anaerobic } \\
4 \text { aerobic } \\
3 \text { anaerobic } \\
3 \text { anaerobic } \\
4 \text { aerobic } \\
2 \text { aerobic } \\
2 \text { anaerobic }\end{array}$ & $\begin{array}{l}\text { None } \\
\text { None } \\
\text { None } \\
\text { None }\end{array}$ & $\begin{array}{l}3 \text { anaerobic } \\
3 \text { aerobic } \\
\text { None } \\
\text { None } \\
\text { None } \\
\text { None } \\
1 \text { anaerobic } \\
2 \text { aerobic }\end{array}$ & (1) Gram - bacillus. & $\begin{array}{l}\text { Intestine occluded with } \\
\text { special clamp } 18 \text { cm. } \\
\text { from pylorus. Lived } \\
172 \text { brs. after opera- } \\
\text { tion. K illed with } \\
\text { chloroform. Autopsy } \\
\text { immediately. No peri- } \\
\text { tonitis; local abscess } \\
\text { around clamp. }\end{array}$ \\
\hline 20 & $\begin{array}{l}\text { Jejunum } \\
\text { Femoral blood } \\
\text { Liver } \\
\text { Peritoneum } \\
\text { Exudate around } \\
\text { clamp }\end{array}$ & $\begin{array}{l}\text { None taken } \\
4 \text { aerobic } \\
4 \text { anaerobic } \\
4 \text { anaerobic } \\
4 \text { aerobic } \\
4 \text { aerobic } \\
4 \text { anaerobic } \\
3 \text { aerobic } \\
3 \text { anaerobic }\end{array}$ & $\begin{array}{l}\ldots . . . \\
\text { None } \\
\text { None } \\
\text { None } \\
\text { None }\end{array}$ & $\begin{array}{c}\ldots \ldots \\
\text { None } \\
\text { None } \\
\text { None } \\
\text { None }\end{array}$ & $\cdots \ldots \ldots \ldots \ldots$ & $\begin{array}{l}\text { Occlusion clamp } 16 \mathrm{~cm} \text {. } \\
\text { from pylorus. Lived } \\
90 \text { hrs. Died. Autopsy. } \\
\text { No peritonitis. }\end{array}$ \\
\hline 21 & $\begin{array}{c}\text { Jejunum } \\
\text { Femoral blood } \\
\text { Spleen } \\
\text { Liver } \\
\text { Peritoneum }\end{array}$ & $\begin{array}{l}4 \text { aerobic } \\
\\
4 \text { anaerobic } \\
4 \text { aerobic } \\
4 \text { anaerobic } \\
4 \text { aerobic } \\
4 \text { anaerobic } \\
4 \text { aerobic } \\
4 \text { anaerobic } \\
3 \text { aerobic } \\
4 \text { anaerobic }\end{array}$ & 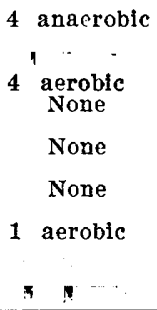 & $\begin{array}{l}4 \text { anaerobic } \\
4 \text { aerobic } \\
\text { None } \\
\text { None } \\
\text { None }\end{array}$ & $\begin{array}{l}\text { Gram + coccus. One } \\
\text { colony only, probably } \\
\text { air contamination. }\end{array}$ & $\begin{array}{l}\text { Occlusion clamp on jeju- } \\
\text { num } 16 \mathrm{~cm} \text {. from py- } \\
\text { Jorus. Dog lived } 58 \\
\text { hrs. Autopsy } 8 \text { hrs. } \\
\text { post mortem. Peri- } \\
\text { toneum clean. }\end{array}$ \\
\hline
\end{tabular}


TABLE 2.-CONTINUED

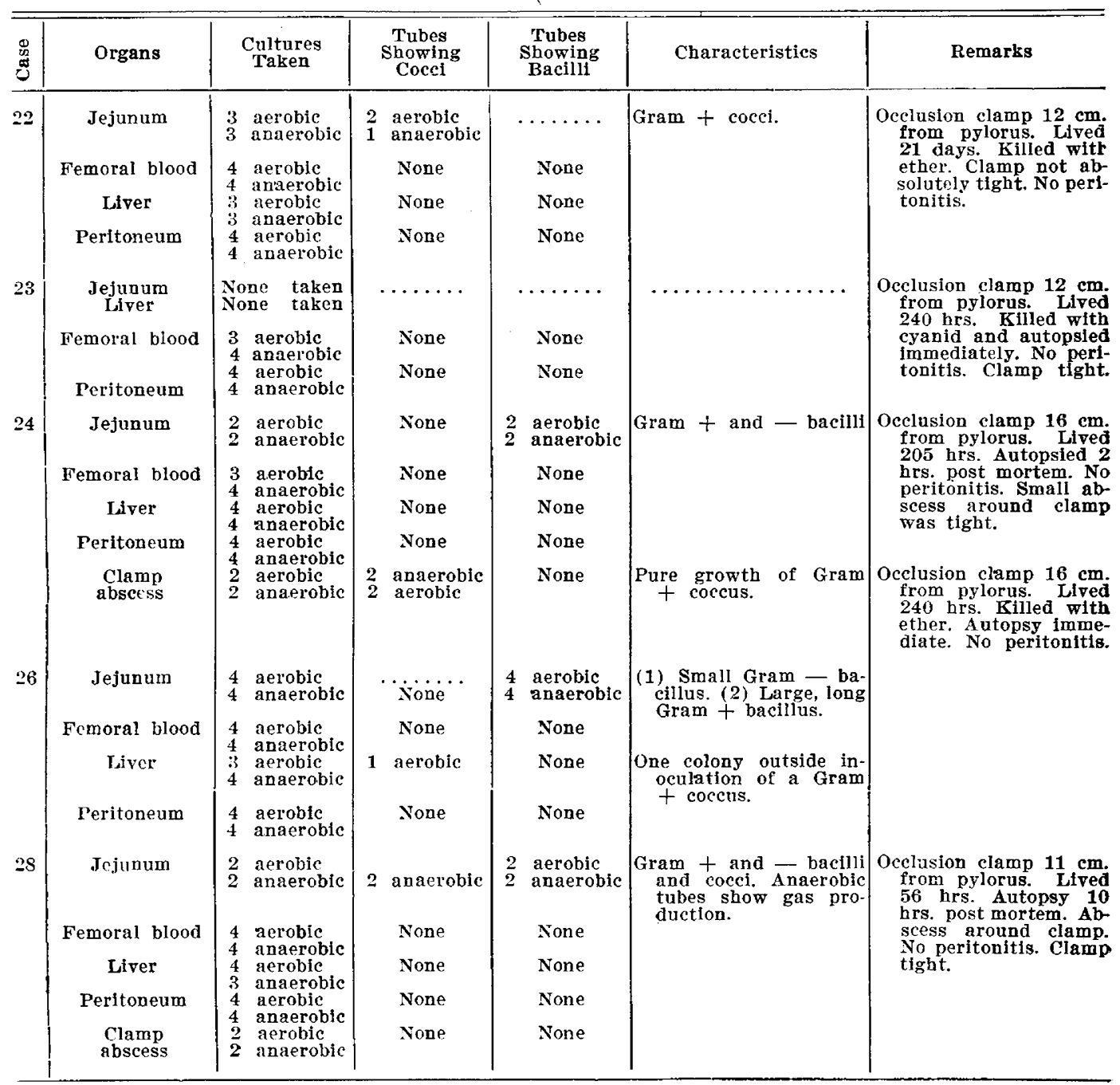

Case 22, given in Table 2, is not included in the summary because the obstruction was not complete. It is worthy of note here, however, that the jejunal tube only showed a growth of a Gram-positive coccus in one-half the tubes inoculated, showing that the long period (twentyone days) with only sterile water by mouth did much toward sterilizing the upper bowel.

It is thus demonstrated that no matter what the rôle of the microorganisms may be within the bowel, or no matter how active they may sometimes become in causing complications by penetration of the bowel into the general system, this is not a necessary factor either in causing 
the symptoms of the disease or in determining the fatal outcome. The theory, therefore, which holds a bacteriemia as the responsible factor in the death following intestinal obstruction is untenable.

\section{THE INTOXICATION THEORY}

This theory, on the contrary, has experimental evidence to support it, and no experiments have proved the absence of a toxemia. Clairmont and $\operatorname{Ranzi}^{8}$ demonstrated that the stagnated material above an obstruction, after passage through a Reichel or Pukal filter, was exceedingly toxic when injected into the blood of an animal. Kukula ${ }^{9}$ found a toxic material in the alcoholic extracts of the intestinal contents in experimental ileus. Roger, ${ }^{10}$ and Roger and Garnier, ${ }^{11}$ went farther and proved that the normal content of both the stomach and the intestine are poisonous when thus injected. They did not filter it, but death occurred too early to be the result of an infection. The toxicity was only one-third as great when injected into the portal vein as when injected into a peripheral vein. They also injected it into a mesenteric artery, against the current, so that it was carried backward and then redistributed through branches to a considerable section of the intestine. Here it produced emboli and stopped the absorption, so that large doses were not fatal.

Murphy and Vincent ${ }^{12}$ found that the material from the obstructed or strangulated intestine was very poisonous when injected into the peritoneal cavity, and that its poisonous properties were destroyed by boiling or passage through a Berkefeld filter. They concluded, therefore, that living bacteria are the important factors. It does not seem to us that this conclusion is tenable. Their experiments only prove that living bacteria, if they obtain entrance into the peritoneum, will kill.

Whipple, Stone and Bernheim ${ }^{3}$ worked with a material obtained from the doubly occluded duodenum, and determined that it was very poisonous even after being rendered sterile. They also found what they believed to be the same poison in the mucosa of this part of the intestine, when one end of it was closed and the other end allowed to drain externally. They applied their results to a simple intestinal obstruction, and concluded that death in this condition is caused by a peison arising from the duodenal mucosa. Their views are opposed in important particulars to the results obtained by us, and will receive closer study later. In general it may be stated that the symptoms aris-

8. Clairmont and Ranzi: Arch. f. klin. Chir., 1904, lxxiii, 696.

9. Kukula: Arch. f. klin. Chir., 1901, lxiii, 773.

10. Roger: Rev. Scient., 1907, xlv, 65; Presse méd., 1911, xix, 1.

11. Roger and Garnier: Arch. de méd. expér., July, 1906; Rev. de méd., 1906, xxvi, 609; Presse méd., 1906, xiv, 325.

12. Murphy and Vincent: Boston Med. and Surg. Jour., 1911, clxv, 684. 
ing from the injection of intestinal contents into the blood, as reported, differ very markedly from those appearing in the obstructed animal, and there are many objections, as pointed out by Guibe, ${ }^{13}$ Braun and Boruttau, ${ }^{4}$ Korentchevsky, ${ }^{14}$ and others, against accepting these experiments as directly bearing on the cause of death in intestinal obstruction. The lessened absorption from the obstructed intestine is one objection offered. Clairmont and $\mathrm{Ranzi}^{8}$ found that potassium iodid placed in the bowel above the obstruction was excreted from the kidneys in greater quantities than normal, up to eight or ten hours after the obstruction was produced; the excretion rapidly decreased after that, and came to a stop in about fifteen hours.

Braun and Boruttau ${ }^{4}$ gave strychnin to their obstructed animals, and from the resulting symptoms they concluded that absorption became markedly reduced from the start. On this experiment they base their chief objection to the intoxication theory. A more important objection to the use of the evidence of the injection experiments as a proof of the intoxication theory is that many substances injected directly into the circulation are poisonous, whereas, if they have to pass through living cells to get into the blood, their poisonous properties are entirely destroyed. Peptone is such a substance, and is a good illustration in this connection. The injection of peptone into the blood produces symptoms of poisoning, which may end in death. The absorption of peptone from the intestine is, on the contrary, a normal physiologic process. Therefore, the mere presence in the obstructed intestinal tract of substances which act as poisons when injected into the blood is no indication that these substances cause the death resulting from an obstruction, since such substances may be normally found in the intestine in conditions of continued health. To accept the view that such a death results from a toxemia it must be conceived either that new poisons are elaborated and absorbed or that an abnormal absorption of the poisons normally takes place.

In undertaking our work, after a study of the literature, we tentatively accepted the first hypothesis and planned our experiments to determine by a process of exclusion from what sources conception was forced on us, namely, that the essential factor in causing the symptoms and death in intestinal obstruction does not lie in the poisons per se, but in the production of lesions which favor their abnormal absorption, and lacking these lesions the animals die only from dehydration, or starvation if dehydration is prevented. We believe our reader will get a clearer understanding of our findings if he will follow, step

13. Guibe: Presse med., 1909, xvii, 233.

14. Korentchevsky: Roussky Vratsch, 1908, p. 1572. :Cited by Guibe, Note 13). 
by step, the reasoning and experiments which led to this change of conception in our minds.

In searching for the source of the poison we accepted three possibilities: (1) foodstuffs or substances derived from them; (2) secretory substances from the alimentary tract and digestive glands, or their derivatives; (3) true bacterial toxins. It was our intention to exclude one after the other of these possible sources and study the conditions resulting after an obstruction was produced. It is readily seen that there may enter into all of these the result of bacterial activity. While, as detailed above, our bacterial studies showed that a bacteriemia is not necesasrily present, they did not exclude either a bacterial toxin or substances developed by virtue of the presence of bacteria in the occluded bowel.

\section{EXPERIMENTS TO DETERMINE THE EFFECT OF FOODSTUFFS OR THEIR} DERIVATIVES ABOVE THE POINT OF OBSTRUCTION

All animals were fully etherized before the operation. No food was given in any case after the operation, unless so stated. Water, however, was given freely, unless otherwise noted.

Experiment 3.-A cat which had received no food for ninety-six hours before operation. Duodenum sectioned and ends closed by inversion $10 \mathrm{~cm}$. below pylorus. For three days the animal remained in good condition. Vomited. Fourth day showed weakness and some rigidity of muscles of extremities. Just before death had convulsions involving extremities. Killed with chloroform ninety-six hours after obstruction. Autopsy immediate. No peritonitis. Closure of bowel ends tight. Stomach contained small amount of normal-appearing gastric content. Duodenum empty. Neither stomach or duodenum was distended.

EXPERIMENT 4.-Fox terrier. Fed twenty hours before operation. Repetition of Experiment 3, the section being $11 \mathrm{~cm}$. distal to the pylorus. Except for some weakness and vomiting, seemed like normal dog for four days. Died with progressive weakness and vomiting on the seventh day. Autopsy. No intestinal leakage. No peritonitis. Stomach slightly distended. Duodenum not distended.

EXPERIMENT 5.-Bitch. Weight $9.8 \mathrm{~kg}$. Fed last time forty-eight hours before operation. Repetition of Experiment 3. Postoperative course the same. Lived one hundred hours. Autopsy. No intestinal leakage. No peritonitis. No distention of stomach or duodenum.

Experiment 6.-Bitch. Weight $10.85 \mathrm{~kg}$. Food withheld for seventy-two hours. Repetition of Experiment 3, section being $12 \mathrm{~cm}$. below pylorus. Postoperative course the same. Temperature varied from 36.6 to $39 \mathrm{C}$. Lived for fifty-five hours. Autopsy. Same findings as those given above.

EXPERIMENT 7.-Dog. Weight $19.7 \mathrm{~kg}$. Fed last time forty-eight hours before operation. Same operation $16 \mathrm{~cm}$. below pylorus. Some peritoneal soiling with intestinal contents. Postoperative course same as others, except more acute. Temperature as high as $39.9 \mathrm{C}$. Lived only thirty-six hours. Autopsy yielded same findings as others.

Experiment 8.-Dog. Medium weight. Fed six hours before operation. Same operation $12 \mathrm{~cm}$. below pylorus. Postoperative course the same. Temperature 39 C. Lived one hundred and eighteen hours. Autopsy. Same findings and in addition there were noted three superficial areas in the duodenum which resembled uicers. 
EXPERIMENT 9.-Leakage of intestinal contents at closed end of proximal gut. Expkriment 10.- Same.

EXPERIMENT 11.-Dog. Weight $5.3 \mathrm{~kg}$. Fed twenty-six hours before operation. Same operation $33 \mathrm{~cm}$. below pylorus. Lived only ten to fourteen hours. Autopsy. No leakage. No peritonitis. Stomach was- not distended. Mucosa showed small punctuate hemorrhages. Intestine proximal to section and for $80 \mathrm{~cm}$. distal to it was much congested and showed hemorrhagic areas in it. We are unable to explain these last post-mortem findings as being the result of the operation. Our belief, however, is that the early death resulted because of them.

Experiment 12.-Bitch. Weight $9.2 \mathrm{~kg}$. Fed twenty-six hours before operation. Same operation $36 \mathrm{~cm}$. below pylorus. Postoperative course as above. Lived eighty-two hours. Autopsy. Same findings as in other cases.

EXPeniment 13.-Dog. Weight $8.2 \mathrm{~kg}$. Fed twenty-six hours before operation. Bowel sectioned $36 \mathrm{~cm}$. below pylorus and ends inverted. Symptoms same as others. Temperature $35.5 \mathrm{C}$. Pulse 180 after twenty-four hours. Lived thirty-eight hours. Autopsy. No peritonitis. Ends of bowel tight. At distal closure an intussusception $14 \mathrm{~cm}$. long had taken place and the intestinal wall was much damaged. This, we believe, contributed to an early death.

EXPERIMENT 14.-Young dog. Weight $5.75 \mathrm{~kg}$. Fed seven hours before operation. Bowel sectioned and ends inverted $31 \mathrm{~cm}$. below pylorus. Never fully recovered from operation and died in twelve hours. Autopsy. No peritonitis. Closed ends tight.

EXPERIMENT 15.-Dog. Weight $10.5 \mathrm{~kg}$. Fed forty-eight hours before operation. Bowel sectioned and ends closed $48 \mathrm{~cm}$. below pylorus. Postoperative symptoms same as in other dogs. Lived thirty-two hours. Autopsy. No peritonitis. Closed ends tight; $10 \mathrm{~cm}$. intussusception of distal end in gut, with much damage of gut wall. Proximal intestinal mucosa showed much congestion and many punctate hemorrhages.

These animals were operated on in a practically identical manner at varying periods after eating, and none was fed anything after operation. The one which lived the longest, one hundred and sixty hours, was fed twenty hours before operation, and the one that died in ten hours was fed the last time twenty-seven hours before operation. One dog which ate a full meal only six hours before operation lived one hundred and sixteen hours, while one that had fasted for seventy-two hours lived fifty-five hours after operation. The dogs had all the water they would take, both before and after the operation.

There is seen to be a complete lack of correspondence between the state of digestion at the time the obstruction is produced on the one hand, and the severity of the symptoms and length of life afterward. The same thing was noted in all subsequent experiments. It seems, therefore, reasonably certain that alterations of food residues in the tract above the obstruction has little to do with causing death.

The condition of the dogs after operation can be very briefly summarized. 'They showed a remarkable absence of active symptoms. Recovery from operation was usually prompt and complete, and on the next day they seemed well, but less lively than before. There was a slight rise in temperature Water was drunk freely, and promptly vomited, washing 
out bile and mucus. Emaciation was marked. After a varying time the animal began to grow weak, but there was a lack of many of the symptoms we are accustomed to see in the human subject. Death seemed to result from general weakness and prostration. There was no abdominal distention, and no sign that cramps or colic were present.

An autopsy was done in every case, and in none was there any gross alteration in the organs that accounted for death. The peritoneum was not inflamed. The stomach and the intestine above the section were sometimes but not always markedly distended. They usually contained only a very small amount of bile and mucus. The mucosa showed a severe congestion. In one or two cases there was a superficial ulceration in the intestinal mucosa. We were struck with the fact that the most severe changes of this character were present in the dogs living the shortest time. We failed, however, to give this observation its full value at that time. The gall-bladder was not distended. The kidneys and liver showed congestion, and the former evidence of degeneration.

From these cases it was determined that animals with a high obstruction might live from five to seven days; that the length of life was not dependent on the presence of food residue in the tract above the obstruction, and that autopsy gave no gross evidence of the cause of death. A complete microscopic study of these cases was not made. Where sections were examined, however, the same lesions were found in the intestinal mucosa, the kidney and the liver, as those to be described in the second group of cases.

We next turned our attention to the production of an obstruction which should not be complicated by any operative damage to the intestinal wall. This was considered advisable because there seemed to be a direct relation between the severity of this damage on the one hand, and the severity of the symptoms and the early death of the dogs on the other.

A special clamp was devised which proved to be efficient in causing a complete obstruction, without opening the intestine or damaging the blood-supply. The clamp consisted of two rubber-covered aluminum plates, about $1 \mathrm{~cm}$. in width and $4 \mathrm{~cm}$. long. Over each end a second covering of rubber tubing was placed. One plate was then passed through a slit in the mesentery, with the bowel passing over it. The second plate was placed across the bowel at this point, and the two plates bound together near their ends. The interval left between them because of the rubber coverings over the ends allowed sufficient room for the intestine, tightly compressed, but not strangulated, to pass through. By bending the plates in or out the degree of obstruction was accurately regulated. We found by experience that the proper degree was obtained when the thin handle of a scalpel could just be passed within the bite of the plates, but not through it. 


\section{EXPERIMENTS WITH OLAMP OBSTRUCTION}

EXPEriment 19.-Male. Weight $13.5 \mathrm{~kg}$. He had been in Iaboratory seventytwo hours without feeding, and had been given only sterile water to drink. This was done with the idea of getting the stomach and upper intestine as nearly free from bacteria as possible. Cushing and Livingood ${ }^{15}$ have shown that the number present can be reduced very markedly in this way. The clamp was placed $18 \mathrm{~cm}$. below the pylorus. The dog remained in excellent condition for five days following the operation. The temperature ranged from 37.5 to $38.5 \mathrm{C}$. and the pulse from 132 to 150 . He drank freely of sterile water, which he vomited soon afterward, washing out bile and mucus with it. He passed small quantities of urine, which contained traces of bile and albumin. During this period he lost $1.8 \mathrm{~kg}$. He showed no active symptoms of the disease, and was in no apparent pain. The abdomen was not tender to palpation, nor was it distended. At operation the circumference of the abdomen was $47 \mathrm{~cm}$. and on the fifth day only $43 \mathrm{~cm}$. After the fifth day he began to show marked weakness and a more rapid loss of weight. The pulse and temperature remained about the same, and no new active symptoms developed. On the seventh day he was markedly weak and walked with difficulty. Emaciation was marked, there having been a loss equal to 19 per cent. of his body weight. He was killed with chloroform one hundred and seventy-two hours after the operation and the autopsy, with bacterial examination, immediately done.

The obstruction was tested under water-pressure, and was found complete, no water passing through the clamped point. Coils of intestine and omentum were matted around the clamp. When these were separated a small local abscess of green odorless pus was opend. The peritoneal coat of the intestine, at this point, was eroded by pressure, but no serious damage was done to the rest of the wall. The general peritoneal cavity was entirely free from evidence of inflammation. The liver and kidneys showed a marked congestion. There was a marked dilatation of the stomach and upper intestinal segment, and both contained water with bile and mucus. Their mucosae were markedly congested.

Microscopical Examination.-The intestine proximal to the clamp shows intense congestion and considerable exudative inflammation of the subserous tissue. The submucosa shows hemorrhagic and leukocytic infiltration. There is an acute hyperplasia of the lymph follicles. Distal to the clamp the intestine is normal. The kidneys show intense capillary congestion, especially of the glomeruli. The epithelium is not well preserved.

The spleen shows congestion.

The pancreas is normal.

The liver sections were unsatisfactory.

The cultures from the abscess around the clamp showed a pure culture of a Gram-negative bacillus, having the characteristics of colon bacillus. Cultures taken from the inside of the intestine, just above the clamp, showed the same bacterial growth, and in addition, a Gram-positive coccus. Our effort to sterilize the upper bowel was not successful, and the local abscess probably resulted from the passage of organisms outward through the intestinal wall, where the peritoneal coat was damaged by the clamp pressure. Other organs were sterile (see table).

EXPERLMENT 20.-Dog. Weight $9.5 \mathrm{~kg}$. No food for one hundred hours. Sterile water during this time. Repetition of Experiment 19. Postoperative symptoms the same. Lived ninety hours. Autopsy (five hours post mortem, during which time the body was on ice) showed no peritonitis. Obstruction complete. Stomach a little dilated. Bowel above clamp twice the normal size. In the intestine, distal to the clamp, were seen many hemorrhagic points.

15. Cushing and Livingood: Johns Hopkins Hosp. Rep., 1900, ix, 543. 
Microscopic Examination.-Intestine proximal to clamp shows fibrinous peritonitis, marked congestion of all coats, and exfoliation of lining mucosal cells. Stomach normal.

Liver: Congestion. Moderate granular and fatty degeneration.

Kidney: Moderate congestion. Tubules show granular coagulum. Cells swollen and show marked granular degeneration. Some cells show partial necrosis.

Cultures from femoral blood, peritoneum and liver show neither aerobic nor anaerobic growth.

EXPERIMENT 21.-Puppy. Weight $8 \mathrm{~kg}$. Fed four hours before operation. Clamp applied $16 \mathrm{~cm}$. below pylorus. The stomach contained food and the lymphatics and vessels were distended from full digestion. The postoperative course was the same as in the others. Pulse, 190. Temperature, $39 \mathrm{C}$. He died fifty-eight hours after operation. Autopsy, eight hours post mortem, the body being on ice. No peritonitis. Moderate distention stomach and duodenum. Few drops of purulent-looking fluid around clamp, buried in adhesions. The obstruction was complete. The gastric and intestinal mucosa, proximal to the clamp, showed very little change. Distal to the clamp there were areas which resembled submucous hemorrhages in the intestinal wall. The other abdominal organs appeared normal.

Microscopic Examination.-Proximal intestine not examined. Distal intestinal mucosa shows hyperplasia of lymph follicle, but no hemorrhages.

Liver: Marked congestion.

Kidney: Congested. Tubule cells swollen, and in places intensely degenerated. Apparent necrosis present in some foci of the tubules.

Spleen and pancreas much congested.

Bacteriology.-Cultures from femoral blood, peritoneum and liver all sterile, both aerobic and anaerobic, with exception of one colony on one peritoneal aerobic slant agar tube. This showed pure growth of a Gram-positive coccus and probably was an air contamination, one of the three found in the whole series.

EXPERIMENT 22.-Bitch. Weight $10.25 \mathrm{~kg}$. Fed eighteen hours before operation. Clamp applied $12 \mathrm{~cm}$. below pylorus. This animal was killed on the twenty-first day, up to which time she had showed no symptoms of suffering or of disease, except for loss of weight to $7.4 \mathrm{~kg}$. During this time she had eaten nothing. She drank water freely, however, for the first three days. After this she received 150 to 250 c.c. of normal saline solution subcutaneously, and then she refused water to drink. She only occasionally vomited. The temperature ranged between 37 and $38 \mathrm{C}$. The pulse for the first four days was about 130. It then became slower and during the last two weeks was between 70 and 100. Urine was passed freely and contained bile and albumin in small quantities. Several blood-cell counts were made during the later days of the experiment and the red cells numbered $5,240,000$ and $7,000,000$, nearly all counts being slightly over 5,000,000. Killed with ether on the twenty-first day while still in good health. Autopsy. No peritonitis. Clamp allowed minimal drainage into intestine below (compare Experiment 27). Stomach and duodenum were somewhat dilated and the intestine distal to clamp was contracted, showing very little flow into it. It contained bile, however, and under pressure water was forced through the clamp into the bowel below. The mucosa of intestine and stomach appeared normal. The kidneys and liver showed congestion.

Microscopic Examination.-Stomach and intestine not examined.

Kidneys: Tubules filled with granular coagulum. Cells show swelling and granular degeneration.

Liver: Intensely congested.

Spleen: Congested.

Pancreas: Normal.

Bacteriology.-Neither aerobic nor anaerobic growth on tubes from femoral blood, liver or spleen. 
Experimen's 23.-Dog. Weight $11 \mathrm{~kg}$. Clamp applied $20 \mathrm{~cm}$. below pylorus. He was killed on the tenth day. His symptoms were the same as in cases above. He received saline subcutaneously with apparent benefit. Pulse, 132 to 150 . Temperature 37.9 to $39.2 \mathrm{C}$. Weight at death $8.5 \mathrm{~kg}$. Urine contained albumin and bile. An extensive noma developed on face which accounted for high temperature. Autopsy immediately after death by cyanid. Obstruction complete. Stomach and proximal intestine much dilated. They contained about 300 c.c. of bile, mucus and water. Distal intestine collapsed. The specimen was preserved intact so the mucosa was not seen. No peritonitis. Liver and kidneys much congested. The latter showed acute degeneration, the markings being indistinct and the papillae pale.

Microscopic Examination.-Kidneys showed granular degeneration, in places very marked.

Liver: Intensely congested. Considerable fatty and granular degeneration.

Spleen and pancreas show congestion.

Bacterialogy.-Aerobic and anaerobic cultures from femoral blood and liver were all without growth.

Experiment 24.-Small bitch. Weight $6 \mathrm{~kg}$. Fed seventy-two hours before operation. Clamp applied $16 \mathrm{~cm}$. below pylorus. Lived 205 hours-a little less than nine days-with symptoms as in other cases. Pulse, 120 to 180 . Temperature average, $39 \mathrm{C}$. Received saline injections throughout. Red blood-cells increased from $5,000,000$ before operation to $6,720,000$ on eighth day, showing some loss of water. Weight $4.9 \mathrm{~kg}$. Died during night. Autopsy at $10 \mathrm{in} \mathrm{morning.}$ Obstruction complete as tested by absence of bile in distal intestine, although under pressure water could be forced bejond the clamp. No peritonitis. Around the clamp in a mass of omentum there was a collection of dirty yellowish fluid. The intestinal wall showed some damage within the bite of the clamp (see microscopic examination). The stomach and proximal intestine were moderately dilated, and contained a small amount of bile and mucus. The mucous membrane of the whole tract appeared normal to gross examination, as did the kidneys and liver.

Microscopic examination.-The intestine within the clamp showed an advanced purulent peritonitis, destroying longitudinal muscular coat. Congestion of mucosa. Exfoliation of epithelium.

Kidney: Congested. Tubules filled with granular coagulum. Cells swollen and show marked granular degeneration; in places approaching necrosis.

Liver: Section lost.

Pancreas: Marked congestion.

Bacteriology.-Aerobie and anaerobic cultures from femoral blood, peritoneum and liver showed no growth. A Gram-positive coccus was obtained in pure culture from the abscess around the clamp in all tubes both aerobic and anaerobic. This was undoubtedly an infection passing through the intestinal wall where the clamp damaged it, since the same organism was isolated from the intestine.

EXPERIment 25.-Dog. Weight $6 \mathrm{~kg}$. Fed twenty-seven hours before operation. Clamp applied $16 \mathrm{~cm}$. below the pylorus. He took ether badly and made a poor recovery. He was not given the hypodermoclysis of normal saline solution. Condition seemed good the next day. Died that night. Autopsy not done till day following, about thirty hours post mortem. Obstruction complete under water-pressure. No peritonitis. Stomach and proximal intestine somewhat distended. Distal gut collapsed. Mucosa of stomach and proximal gut markedly congested. Liver, spleen, pancreas and kidneys show congestion.

Microscopic Examination.-Stomach congested. Proximal intestinal mucosa shows intense congestion. Marked round-cell infiltration of tips of villi and exfoliation of cells.

Liver: Intense congestion. Considerable fatty and granular degeneration.

lidney: Not examined.

No bacteriological examinations made because of delayed autopsy. 
ExPERIMExT 26.-Bitch. Weight $7.2 \mathrm{~kg}$. Exact duplicate in every way of Experiment 25, except that she received the saline injections daily, the first one of 150 c.c. being given at the close of the operation. She lived ten days, and showed the same symptoms as did other dogs described. Killed with ether and autopsied immediately. Obstruction complete against a column of water $90 \mathrm{~cm}$. high. No peritonitis. The stomach and proximal intestine were dilated to about three times normal. The mucosa of stomach and proximal intestine were congested. The liver, kidneys and spleen were congested.

Microscopic Examination.-Proximal intestinal mucosa shows intense congestion and exfoliation of living cells.

Kidney: Shows congestion. Tubules contain coagulum and occasional bloodcells and show granular degeneration, in places very marked.

Liver shows intense congestion, atrophy of liver cords about distended capillaries and moderate granular degeneration.

Spleen shows much hypertrophy of the follicles.

Pancreas normal.

Cultures from femoral blood, spleen, liver and peritoneum were taken. These were all without growth after four days, under both aerobic and anaerobic conditions, except one aerobic tube (four were taken) from the liver. This showed one colony of Gram-positive cocci growing well to one side of the stroke of the loop.

Experiment 27.-Bitch. Weight $11.5 \mathrm{~kg}$. Fed twenty-eight hours before operation. Clamp applied about $15 \mathrm{~cm}$. below the pylorus. Lived twenty-four days with only moderate development of symptoms during first week. Then behaved like a normal dog. Reoperated on July 20. The clamp was not sufficiently tight to make a complete obstruction (compare with Experiment 22). It was tightened and the next day it had cut its way through the intestinal wall and the dog died of a peritonitis.

Experiment 28.-Dog. Weight $6.5 \mathrm{~kg}$. Fed twenty-eight hours before operation. Clamp applied $11 \mathrm{~cm}$. below pylorus. Postoperative course as in other cases. Died in fifty-six hours and body immediately placed on ice. Autopsy ten hours later. Obstruction complete. No peritonitis. Local infection around the clamp. Stomach and proximal intestine only slightly distended and contained a small amount of bile-stained fluid. The distal intestine was totally empty. Two superficial ulcers were seen in the mucosa of proximal intestine. The liver, kidneys, spleen and pancreas appeared normal.

Microscopic Examination.--Intestine not examined.

Kidney: Tubules swollen and show granular degeneration, very marked in places.

Liver: Intensely congested.

Bacteriology.-Cultures from the femoral blood, the peritoneum, the liver, the spleen and the local collection of fluid around the clamp all were without growth under aerobic and anaerobic conditions.

EXPeriment 29.-Dog. Weight $8 \mathrm{~kg}$. Fed thirty hours before operation. Clamp applied $11.5 \mathrm{~cm}$. below pylorus. Postoperative course same as in other cases. Received about one-fortieth of body-weight of normal saline subcutaneously daily. He remained in excellent condition for eight days, during which time he lost a little over $2 \mathrm{~kg}$. in weight. He drank water each day, which was always vomited. Pulse from 130 to 174 . Temperature, 38.5 to $40 \mathrm{C}$. On the ninth day he was etherized and the abdomen opened. The obstruction was complete. The stomach and proximal intestine were much distended and filled with a greenish fluid of the thickness of pea soup. There was no peritonitis. The splanchnic vessels were not much dilated, except those above the occlusion. The spleen was not enlarged. The liver and kidneys did not show much congestion. Sections were taken from the stomach, duodenum, distal intestine, liver, spleen and kidney while the dog was still under ether, after which he was killed.

Hicroscopic Examination.-The stomach is normal. 
The proximal intestine shows marked congestion and an edema in the submucosa. The lesions here were not advanced, because the specimens were taken some hours before the animal would have died from the disease. The distal intestine is normal.

The liver is congested. The cells show granular degeneration and areas of necrosis are present.

The kidney is congested. Tubules contain granular coagula. The cells show granular degeneration.

The preceding series includes experiments on eleven animals which may be summarized. In two a complete obstruction was not obtained because the clamp was not sufficiently tight. The two animals were killed after twenty-one and twenty-four days, respectively, while each was in good condition. They had lost considerable weight, and one of them was weak, but otherwise they acted like normal dogs.

The remaining nine dogs all showed a similar condition while living, and autopsy yielded the same findings in the organs. In some dogs, particularly those which lived the longest, the dilatation of the stomach and the duodenum was very marked.

Four dogs in this series were given sterile water by mouth only, and this they promptly vomited. They were, therefore, practically getting neither nourishment nor water, for if what they drank was not all vomited, very little absorption could take place from the stomach and duodenum. Beginning with the fourth dog, each dog received from 150 to 300 c.c. sterile normal saline solution, subcutaneously, per day. This was absorbed. In one case this was not given till the third day. This animal had then begun to act sick, but showed a marked improvement after the administration of the hypodermoclysis. In general, the dogs which received this saline lived longer than the others. They sometimes drank sterile water in addition, but this they always vomited in a very short time. In many cases they refused to drink more than a few cubic centimeters. The three dogs which lived the longest were all given the saline subcutaneously, and there seems no doubt that this procedure was very beneficial.

We attempted, by a count of the red blood-cells, to determine whether the dogs not receiving it suffered from dehydration, with a consequent increase in the number of red cells per cubic centimeter. There was not a sufficient variation from the normal to throw any light on this point, the number ranging around $6,000,000$ both before and after the saline injections. The longest postoperative life was ten days (two dogs)' a third dog lived just under nine days; the shortest period was thirty-six hours in a small fox terrier which never completely recovered from the operation. The average length of life was one hundred and thirty-nine hours in this series, as against sixty-seven hours in the series in which the obstruction was produced by sectioning the intestine and inverting the ends. It was only in this series that the saline injections were used. 
It was, moreover, remarked that the second series, in which no damage to the intestinal wall was produced, was much nearer the normal throughout the experiment than was the first series, in which the intestine was sectioned. So far as we know, no other investigator has paid the same attention to producing an obstruction without any damage to the intestinal wall. There is evidence that the method is of advantage in excluding the complications which may arise from such damage. Clinically, we know that when a strangulation, however limited in extent, is superimposed on an obstruction, the course of the disease becomes much more acute. Medowoy, ${ }^{18}$ Kocher $^{17}$ and others emphasize this point.

Murphy and Vincent, ${ }^{12}$ in their experiments, worked particularly on this phase of the question. In a simple obstruction in cats they found the intestinal wall very little damaged in four to six hours. When, however, the circulation was disturbed, particularly a venous stasis produced, a very severe change was present at this time. They conclude that "interference with the circulation of the obstructed intestine is the vital factor in the production of the symptoms of ileus."

When the intestine is sectioned, and the proximal end sufficiently inverted to prevent the stomach and duodenal contents being forced through it, a local strangulation takes place. At autopsy there was always found in these cases a local damage to the intestinal wall at the inverted point, small in extent, to be sure, but nevertheless sufficient to be the possible site of the absorption of a considerable amount of poison. Often, too, a very considerable intussusception of the invaginated stump was present. This mechanical damage, of course, is not an essential in producing death, because it was not present in the second series, in which the animals died. We feel, however, that it has an important bearing on the problem, as we shall later more fully explain.

We desire to call particular attention to the microscopic findings in these cases. The intestinal mucosa, proximal to the obstruction, shows a marked congestion. Marked round-celled infiltration is present, and exfoliation of the lining cells. Hemorrhages are often seen. There is present an acute hyperplasia of the lymph follicles. The submucosa is edematous. Distal to the clamp there is no change, or only a very slight change, from the normal. The gastric mucosa shows only a congestion. The kidneys are markedly congested. The tubules contain granular coagula. The tubule cells are swollen and the seat of granular degeneration; not infrequently necrotic areas are seen.

The liver is congested and the cells show granular and fatty degeneration. Necrotic areas may be present.

16. Medowoy: Deutsch. Ztschr. f. Chir., 1910, cv, 1.

17. Kocher: Mitt. a. d. Grenzgeb. d. Med. u. Chir., 1898-99, iv, No. 2, p. 195. 
The spleen shows marked congestion, and some hyperplasia of the Jymph follicles.

The pancreas shows only congestion.

The changes in the intestinal mucosa are worthy of careful study. They may result from two causative factors. The marked distention and stretching of the intestinal wall may produce a circulatory disturbance or possibly an actual trauma to the mucosa. The stagnated secretions may be sufficiently irritating to damage the mucosal cells chemically. In either case there would develop a condition of lessened resistance, and the intestinal bacteria would be free to attack the mucosa and bring about the changes seen. This having occurred, the changes in the other organs may be conceived as having been caused by the entrance into the blood of poisonous materials which were produced by this bacterial activity. Sufficient evidence that such an explanation is correct is found in the fact, already pointed out, that there is an apparent parallel between the extent of the changes in the mucosa and the severity of the symptoms.

The evil effects of hyperdistention to the intestinal circulation has been experimentally shown by Van Zwalenburg. ${ }^{18}$ By means of illumination in the intestinal lumen he watched the circulation when different degrees of pressure were exerted inside the bowel. At a pressure of $30 \mathrm{~mm}$. mercury it was noted that some capillary streams were arrested, while at $60 \mathrm{~mm}$. small veins became blocked. Above this the circulation showed increasing disturbance. If a continuous pressure of irom 80 to $90 \mathrm{~mm}$. were continued for an hour, the apparent number of veins seen on the serous surface was greatly increased. Their caliber was also greater than normal. This observation would seem to indicate that the effect of the long-continued distention in a blocked bowel must seriously damage the integrity of the mucosal circulation and lead to the lesions observed in our experiments and recorded above.

The influence of the stagnated secretions above the obstruction may be considered as important in giving rise to poisonous materials which could enter the circulation through the damaged intestinal wall. In order to study this phase of the question, we turned our attention to an elimination of the bile, pancreatic and duodenal secretions as a source of the poisons. To this end, in five dogs the following operation was done: T'he pylorus was divided and the two cut ends closed by inversion. The intestine was divided just distal to the duodenum, and the proximal end implanted in the jejunum about $30 \mathrm{~cm}$. lower down. The distal end was implanted into the stomach. By this means the stomach emptied into the intestine just below the duodenum, and the bile, pancreatic and duodenal secretions passed into the jejunum about $30 \mathrm{~cm}$. distal to this. Our intention was to cause an obstruction with the clamp, just orally

18. Van Zwalenburg: Ann. Surg., November, 1907, xlvi, 780. 
to the new duodenal outlet when the animals should have recovered from the anastomoses, thus having an obstruction of the stomach and about $30 \mathrm{~cm}$. of the intestine but not of the duct-bearing portion of the tract. For a few days following the operation these dogs did well, fully regained their appetites and seemed to be in good health. After about a week, however, they began to act sick. They did not eat well, and sometimes vomited. They lost weight rapidly. Some of them developed diarrhea with bloody-appearing stools. Four of them died in about four weeks with evidence of malnutrition. The autopsy showed, in two of these, that a very extensive damage to the intestine between the stomach and duodenal anastomosis was present. Ulcers were seen which were about to perforate. The stomach and this part of the intestine contained partially digested blood.

The fifth dog seemed to be in fair condition after two weeks, and on the nineteenth day the abdomen was opened under ether anesthesia. The anastomoses were satisfactory and no evidence of ulceration was present from the peritoneal surface. The occlusion clamp was applied just above the anastomosis of the duodenum with the jejunum. The following day the dog was in good condition; he had not vomited. $\mathrm{He}$ was given saline subcutaneously. He died during that night and autopsy was done in the morning. The anastomoses were satisfactory. A general peritonitis was present from a perforation within the bite of the clamp. The stomach and intestine anastomosed to it were distended with a dirty brownish fluid. When they were opened the gastric mucosa was seen to be much congested; the mucosa of the jejunal segment was markedly congested and contained many hemorrhagic areas. The intestine below the duodenal anastomosis was entirely normal in appearance. The effort to produce an obstruction in which the duodenal contents should not be stagnated had not been successful. But the symptoms developing in these dogs and the findings in the intestinal mucosa added emphasis to the relations existing between these two factors. In many ways these dogs behaved like the ones with an obstruction, the symptoms and the course of the disease being, however, much less acute. The microscopic examination of the intestinal mucosa, the kidneys and the liver, showed, too, the same lesions as found in the simple obstruction.

The fact that such damage to the intestinal wall, in so far as it occurs in intestinal obstruction, is the cause of serious symptoms, and, if extensive enough, may even cause death, seemed to be well demonstrated. That it is the sole factor, however, was not proved, and as stated above, our attention had been arrested by the benefit derived from the administration of salt solution under the skin. It was conceivable that this benefit arose from diluting and eliminating the poisons absorbed through the damaged intestine. Such a supposition, however, had no support in any work done, and accordingly a more detailed study of this question was 
undertaken, and for this purpose Dr. Benedict, of the department of chemistry, kindly offered to make some studies in metabolism for us. To him we are indebted for a most important discovery which, we believe, throws much light on the question under consideration, if it does not completely solve the problem of the cause of death from uncomplicated intestinal obstruction.

Experiment 1.-The first dog under his observation was a female in good condition, weighing $12.1 \mathrm{~kg}$. The clamp was applied under ether narcosis on the lower part of the duodenum, March 4, 1912. Table 3 gives the results found during the three and a half days that she lived.

TABLE 3.-RESULTS OBTAINED AFTER CONSTRICTION OF THE LOWER PART OF THE DUODENUM FOR THREE AND ONE-HALF DAYS

\begin{tabular}{|c|c|c|c|c|c|c|}
\hline Date & Weight, & $\begin{array}{l}\text { Urine, } \\
\text { c.c. }\end{array}$ & $\begin{array}{l}\text { Vomitus, } \\
\text { c.c. }\end{array}$ & $\begin{array}{c}\text { Combined } \\
\text { Fluid } \\
\text { Output, } \\
\text { c.c. }\end{array}$ & $\begin{array}{l}\text { Total } \\
\text { Nitrogen, } \\
\text { gm. }\end{array}$ & Renlarks \\
\hline $3 / 4 / 12$ & 12.10 & . & $\ldots$ & $\ldots$ & $\ldots$ & Clamp applied to lower \\
\hline $3 / 5 / 12$ & 11.28 & 26 & 720 & 746 & $\cdots$ & $\begin{array}{l}\text { Received } 100 \text { c.c. of a } \\
0.9 \text { per cent. saline } \\
\text { solution. }\end{array}$ \\
\hline $3 / 6 / 12$ & 10.36 & 15 & 500 & 315 & 10.334 & $\begin{array}{l}\text { Received } 100 \text { c.c. of a } \\
0.9 \text { per cent. saline } \\
\text { solntion. }\end{array}$ \\
\hline $3 / 7 / 12$ & 9.86 & 86 & 510 & 596 & $\cdots$ & $\begin{array}{l}\text { Received } 100 \text { c.c. of a } \\
0.9 \text { per cent. saline } \\
\text { solution. }\end{array}$ \\
\hline $3 / 8 / 12$ & 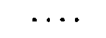 & $\cdots$ & $\cdots$ & $\cdots$ & $\cdots$ & Died. \\
\hline Totals, & $\ldots$ & 127 & 730 & 857 & $\cdots$ & \\
\hline
\end{tabular}

From these figures it is seen that she lost $2.2 \mathrm{~kg}$. in weight. Her output of fluids, including the urine and vomitus, but not counting the water of expiration, was 1,857 c.c., to offset which she had only received 300 c.c. subcutaneously. The total nitrogen output in two days was $10.34 \mathrm{gm}$. , which equals, approximately, 0.5 gm. per kilo per day, which is two or three times the normal output. A sample volume of urine of 127 c.c. contained $3.574 \mathrm{gm}$. albumin. The creatin excreted in this equaled $0.638 \mathrm{gm}$., which was more than double the amount of creatinin.

It was obvious from these figures that a very severe grade of tissue disintegration was taking place, and that a water loss averaging about 5 per cent. of the body weight was suffered each day. It at once became apparent that the amounts of water we had been giving were entirely inadequate to replace this great loss, and that probably death was much hastened by such a loss.

Accordingly, we made a study of three dogs in which the daily output was measured, and a quantity of normal saline about 100 c.c. in excess of this was injected under the skin. These dogs with the clamp applied on the lower duodenum were kept alive in this way for three weeks (one for twenty-six days), and during this time they remained in good condition. They were then etherized a second time, and the abdomen opened to see if the obstruction were complete. In every case it was found to be so. The stomach and the duodenum above the clamp were excessively dilated, and their contents could not be forced through the 
clamp into the intestine below, which was found empty and much contracted. By varying the amount of water injected, we could accurately control the condition of the dogs. The complete study of one of the experiments is shown below.

TABLE 4.-RESULTS OBTAINED WITH CLAMP ON THE DUODENUM FOR THREE WEEKS AND INJECTIONS OF SODIUM CHLORID

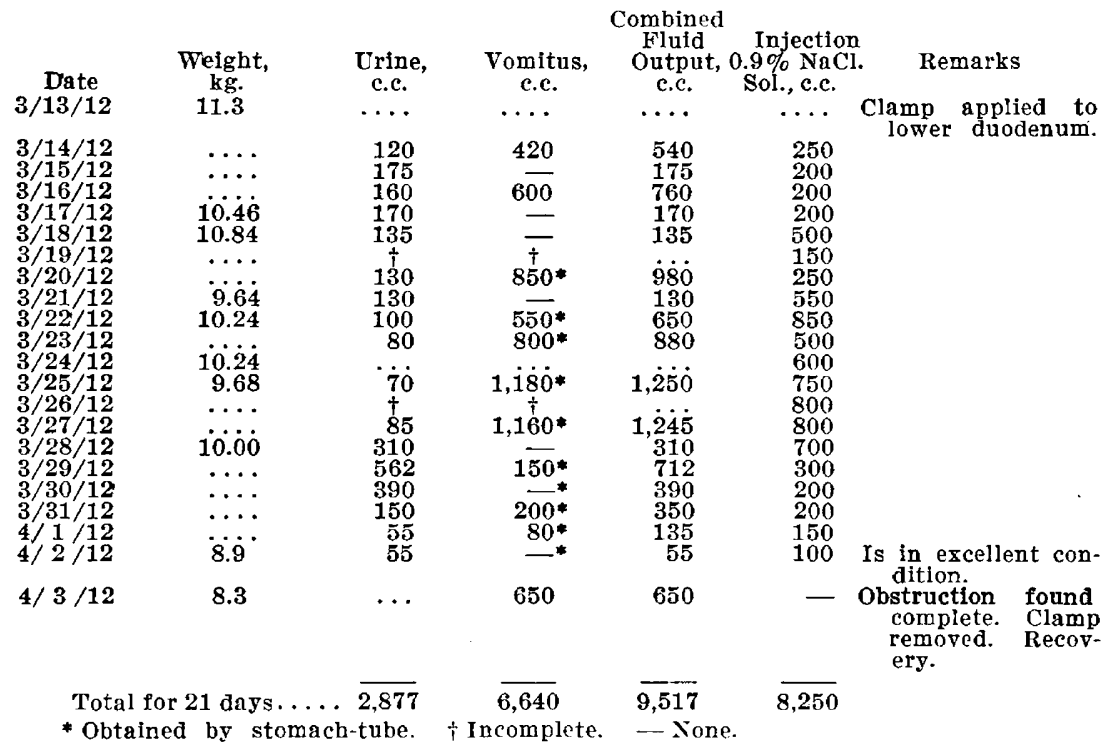

EXPERIMENT 2.-A bitch weighing $11.3 \mathrm{~kg}$. had the clamp applied under ether narcosis, on the lower duodenum, March 13. April 3, twenty-one days later, when in excellent condition, she was again etherized and the abdomen reopened. The obstruction was found to be complete. The clamp was removed and she is still alive. The total vomitus during the twenty-one days was 6,640 c.c. and she received to offset this 8,250 c.c. of saline solution. Much of the vomitus had to be obtained by the stomach-tube, as the stomach became dilated and would not empty itself. She lost $3 \mathrm{~kg}$. in weight. The study of the urine gave most interesting results. During the first week it showed very marked abnormalities. The albumin content was as high as $4.5 \mathrm{gm}$. per day, and the total nitrogen, exclusive of this, was, on an average, $\tilde{\mathbf{5}} \mathrm{gm}$. The creatinin-creatin ratio was about $I$ to 2 instead of 10 to 1 , which is near the normal for a starving dog. The latter ratio was later established. During this week the vomitus was 1,870 c.c. in amount, which was 120 c.c. more than the amount of saline solution administered. The urine equaled 890 c.c., so that there was a loss of water equal to one-tenth of the body-weight. The condition of the animal was only fair during this week. After the seventh day the saline was increased to 550 c.c. daily and maintained there, or higher, for several days. The abnormalities in the urine entirely disappeared, and it became the urine of a dog under normal starvation, except that it contained bile throughout. There was coincident improvement in her condition. Later, on the sixteenth day when vomiting had ceased and the stomach-tube recovered very small amounts, the saline was again decreased to 200 c.c. or less; the dog remained well, and the urine continued normal.

ExPERIMENT 3.-A small bitch weighing $5.88 \mathrm{~kg}$. had the clamp applied under ether narcosis to the lower duodenum, April 8, 1912. She received the normal 
saline solution subcutaneously, every day, the first injection of 300 c.c. being given immediately after the operation. The quantity was repeated on the two following days, and then for sixteen days she received 400 c.c. daily, and for two additional days 300 c.c. each. The total saline administered during the continuance of the experiment for twenty-one days was 7,900 c.c. an average of 376 c.c. per day, which was equal to about 8 per cent. of her average body-weight. During this time the total amount of fluids excreted in the urine and the vomitus was 6,354 c.c. Much of the vomitus had to be excreted by means of the stomachtube because the stomach became atonic and vomiting ceased even though the organ was full. Her loss in weight was $1.4 \mathrm{~kg}$. Throughout the entire experiment she remained in a condition of apparent perfect health. She was always playful and lively. On the twenty-first day she was etherized and the abdomen. was reopened. The clamp was found in situ and the obstruction was complete. Four hundred and fifty c.c. of water were put in the stomach through the tube. This readily passed through the pylorus and down the duodenum to the clamp, where it was completely stopped. It was impossible to force any beyond the clamp by direct pressure on the duodenal wall. The clamp was removed and a small perforation, which was completely closed by the rubber covering of the plate and by adhesions, was found in the bite of the clamp. There was no peritonitis.

EXPERIMENT 4.-A bitch weighing $12.2 \mathrm{~kg}$. had the clamp applied under ether narcosis to the lower duodenum, April 19, 1912. During the following six days she received 1,500 c.o. of normal saline solution subcutaneously, and excreted in the form of vomitus and urine 1,020 c.c. On the seventh day she did not vomit, and the stomach-tube recovered nothing. We suspected that the clamp was not tight enough to produce a complete obstruction, and she was accordingly given 500 c.c. of water through the stomach-tube and a quantity of meat which she ate greedily. Following this she again vomited, and in four days put out 2,150 c.c. in which the digested meat was present. The injections were then increased, quantities varying from 700 to 500 c.e. being given daily. The vomiting ceased and a quantity of urine was passed, slightly less than the saline injected, the total for seven days being, saline 4,000 c.c., urine 3,200 c.c. The saline was again decreased, and the urine fell, but no vomiting recurred. She was etherized May 16, twenty-six days after the obstruction, and the abdomen was reopened. The obstruction was found to be complete. The stomach and duodenum were found to be enormously dilated, having a capacity of 1,000 c.c., while the intestine below the clamp was contracted and empty, not showing any trace of bile. No detailed study of the urine was made in this or the preceding case.

It will be noted that in many instances there was no vomiting, but the stomach-tube recovered large quantities. This must be taken into account in determining the amount of saline to be administered, because whether vomited or retained in the stomach, it means a loss to the animal. These three dogs were under identical conditions with the nine previously reported, except that they received amounts of normal saline solution about 100 c.c. in excess of the daily output of vomitus, often reaching 500 to 700 c.c. per day, while the animals in the former series received only 150 or 200 c.c. per day. No dog in the first series lived longer than ten days. All dogs in the later number were alive and in good condition at the end of three weeks, and apparently would have succumbed only to starvation if the experiment had been continued.

In order to be certain that no leakage took place, an obstruction was produced in two dogs by dividing the lower duodenum and closing the 
ends by inversion. The result was the same as in the dogs having the clamp applied. Care must be taken, however, to minimize the amount of damage done to the intestinal wall in this operation, otherwise the animal is poisoned from this source and may die.

From these results it is plain that the loss of fluid from the organism is the disturbing influence and is the important factor in explaining the symptoms and death following uncomplicated high intestinal obstruction in dogs. Death is caused by the loss of water which the tissues sustain from the excessive amounts vomited, and death can be prevented if this water be replaced by cutaneous injections of normal salt solution.

The source of such enormous amounts of vomitus is a matter of interest. Dr. Benedict's study of the vomitus from the experiment detailed under Table 4 showed it to be strongly acid, and to have a specific gravity of $1.00 \%$. The total amount contained $16.72 \mathrm{gm}$. of chlorin, which, computed as sodium chlorid, equals $27.65 \mathrm{gm}$. Bile was always present. The low specific gravity indicates that it was largely water. These findings show, as would be expected, that the vomitus is a diluted mixture of bile and gastric secretion. The part played by the pancreas and duodenum is unknown. In all the cases the vomitus was more abundant during the early part of the experiment than it was later, and toward the end it often almost entirely disappeared. The following considerations offer an explanation of this unexpected fact. The dogs were all in good condition when operated on, and presumably the liver and other glands were actively secreting. The products of these glands, bile, pancreatic juice and duodenal secretion, found no outlet beyond the duodenum, and hence were forced back into the stomach. Here they acted as an irritant to the gastric mucosa, and as a result a secretion of gastric juice and an excretion of water took place to the enormous amounts found. As the experiment proceeded the dog gradually developed the condition of a starving animal in which all the alimentary glands become inactive, the bile in particular being very small in amount. The disturbing influence of these retained secretions being absent, the vomiting gradually grows less, and finally almost ceases. The small amount of bile secreted is taken care of in the duodenum and stomach, being either digested or absorbed. That some is absorbed is shown by the fact that the urine contains bile throughout the experiment. The bile alone, however, is not the offending factor, because in cases in which the common bile-duct was tied and an anastomosis made between the gall-bladder and the intestine below the clamp, large amounts of vomitus appeared, though not equaling those above given.

The results of all our work demonstrated, therefore, that there are two important factors concerned in producing the symptoms and causing death in a high intestinal obstruction in dogs. 
First, the loss of water from the tissues caused by the excessive drainage into the intestinal lumen followed by vomiting. This factor is entirely under therapeutic control. It can be rendered harmless by the subcutaneous administration of normal saline solution.

Second, the absorption of poisonous materials from the intestinal wall, when, by reason of overdistention and chemical irritation the mucosa is damaged and bacteria set up an active inflammation in it, and possibly the other intestinal coats. This factor is not appreciably influenced by the administration of the salt solution.

\section{REVIEW OF THE WORK OF WHIPPLE, STONE AND BERNHEIM}

We have referred above to the work done by Whipple, Stone and Bernheim, which appeared ${ }^{3}$ after preliminary reports of our work had been published, ${ }^{10,20}$ setting forth the conclusions just given. As their conclusions differ in important particulars from ours, it seems advisable to compare the two, and if possible reconcile the facts as a basis for the correct conclusion. In doing this we shall quote freely from an article already published, ${ }^{21}$ in which this phase of the subject was treated.

Whipple, Stone and Bernheim, ${ }^{22}$ studied the question by producing a closed loop of the duodenum, beginning just below the pancreatic ducts and ending beyond the suspensory ligament. This portion was isolated from the remainder of the intestinal tract by tying a heavy ligature tightly at these two points, and burying it under an inverted layer of the peritoneum. A gastro-enterostomy was then done. Dogs so treated died in from thirty-six to seventy-two hours. The authors inferred from this that there developed in the closed loop a poisonous material, the absorption of which caused death. Since the closed loop contained neither gastric secretion, bile nor pancreatic juice, the conclusion seemed inevitable that some alteration in the loop function was responsible for death.

A series of careful and well-controlled eperiments was then undertaken to study the nature, and if possible, to determine the source of any poison. The method employed was to produce the isolated loop, collect the contents, sterilize them by heating to $60 \mathrm{C}$., filtering them, and then, after autolysis, to inject them into a healthy dog, intravenously, subcutaneously or peritoneally. It was demonstrated in this way that dogs so injected died promptly. Further, the authors were unable to isolate any poisonous material from the normal intestine by any method of treatment; and if the mucosa of the loop were first destroyed by a

19. Hartwell and Hoguet: Am. Jour. Med. Sc., 1912, exliii, 357.

20. Hartwell and Hoguet: Experimental Intestinal Obstruction in Dogs, with Especial Reference to the Cause of Death and the Treatment by Large Amounts of Normal Saline Solution, Jour. Am. Med. Assn., 1912, lix, 82.

21. Hantwell, John A.: Jour. Exper. Med., 1913, xviii, No. 2, p. 139.

22. Whipple, Stone and Bernheim: Jour. Exper. Med., 1913, xvii, 286. 
fluorid, no poisons appeared. Lastly, some dogs died within a few days when the loop was drained externally, there being, according to the authors, an absorption directly from the mucosa, and not from the lumen.

The authors summarize, in part, as follows:

' 2 here seems, therefore, no escape from the conclusion that a poisonous substance is formed in this closed duodenal loop which is absorbed from it and causes intoxication and death. Injection of this toxic substance into a normal dog gives intoxication and a reaction more intense than, but similar to, that developing in a closed loop dog (p. 306).

The mucosa of closed or drained duodenal loops contains a toxic substance quite similar to the toxic material found in the lumen of the closed loops.

Normal intestinal mucosa contains no toxic substance nor can it neutralize in vitro the toxic substance produced in the closed loops. Our experiments show that formation and absorption of a toxic substance may proceed in a loop whose blood-supply has in no way been disturbed, and whose mucosa is quite intact both in gross and microscopically (p. 323).

The authors apply their findings to the condition of simple intestinal obstruction, and state it as their belief that "the toxic material concerned is the same in both instances" (p. 321). They add: "Our experiments indicate that intoxication is the primary effect, and the loss of body fluids a secondary one, rather than the reverse, as is claimed by Hartwell and Hoguet."20 In substance, they claim to have proved that a closed loop of intestine, without undergoing any morphological change, produces a toxic substance which is absorbed and causes death. Moreover, they infer that a similar condition exists in simple intestinal obstruction, and that here also death results from the absorption of this same poison.

We fail to find any evidence in their experiments, as published, to justify these claims. On the contrary, we find that the protocols definitely show a damage to the intestinal wall, and that the toxic substance they are dealing with arises from this source. In the absence of this damage no toxemia is present except that produced by the loss of water in the vomitus. We submit the following review of their protocols in support of this view:

Doo S-34.-Moribund in twenty-seven hours. Killed with ether. Autopsy immediately. "The duodenal loop is of enormous size." "Purplish patches show through the transparent serosa." "The contents are blood-stained."

Microscopical Examination.- "In places the wall of the duodenum shows necrosis, hemorrhage and invasion by leukocytes."

Dog S-27.-Died in thirty-two hours.

Autopsy.- "The duodenal loop is contracted and contains a little material. Its walls show a few areas of subserous hemorrhage, about 1 or $2 \mathrm{~cm}$. in diameter. There is obvious necrosis associated with these areas, and through one of them rupture had taken place, with escape of duodenal loop fluid into the peritoneum." No microscopical examination is given.

DoG S-20.-Death in forty-eight hours. One hundred c.c. of fluid are in the loop. "The closed loop mucosa is pinkish and a little swollen, but no ulcers are present." The proximal loop was not tight, and some fluid had probably regurgitated into the stomach. 
Dog 56.-Death in fifty-five hours. Remained well for twenty-four hours.

Autopsy.- "The abdominal cavity is clear except for slight granular peritonitis about the loop and area of operation." "The small intestine below the loop contains blood-stained mucus, and its mucosa has a mottled appearance, with large areas of deep red color where the capillary injection is quite marked. The duodenal loop is rather flabby and not greatly distended. It contains about 50 c.c. of a thin, soup-like, faintly blood-tinged fluid. The loop mucosa is quite intaet, but of a delicate pinkish tinge." No microscopical examination is given.

Dog S-53.-Death in three days. Seemed well for twenty-four hours.

Autopsy.-The condition of the loop mucosa is not given; it is merely stated that it is pink and intact. No microscopical examination is given.

Commenting on these four experiments the authors say:

The duodenal loop may show a normal intact mucosa in gross and microscopically, except for a little diffuse injection. Again, it may show necrosis, ulceration and hemorrhage, and the contained fluid may vary correspondingly in characteristics, but it always contains a toxic substance (p. 291).

In only one case, however, is a microscopical examination given, and then marked changes were found, while in the others evidence of change was seen grossly. The length of life seems directly to correspond to the lack of damage found in the mucosa, as demonstrated by the reported findings in Dog S-53, which lived for three days.

The following protocols give the conditions found in the duodenal loop, when the dog is killed at the end of twenty-four to twenty-eight hours. In one case, Dog S-4, the contents were blood-tinged, owing to inversion of the duodenal mucosa.

Dog S-4.- "The mucosa throughout the loop is intact, but slightly swollen and of a pinkish color."

Microscopical Examination.- "The tips of a few of the villi are slightly swollen and contain a few polymorphonuclear leukocytes. The epithelium is normal throughout."

DoG S-2.-In twenty-six hours the duodenal loop contained blood-tinged fluid; in places, on microscopical examination, "it shows some areas of necrosis with hemorrhage and invasion by pus cells, involving mucosa and submucosa."

Doo S-5.-The loop contained blood-tinged fluid.

Microscopical Examination. - "The duodenal loop is quite normal."

In two dogs, S-28 and S-29, the duodenal loop contents were not blood-tinged, and the mucosa, on gross examination, seemed normal, though no microscopical examination is given.

These dogs were all in fair condition when killed, being described as "dull and drowsy," "weak," "pulse strong," "somewhat dull but not very toxic." The incipient damage to the mucosa, as shown in these cases by the blood-tinged fluid and the microscopical examination, explains the cause of their condition. We cannot reconcile a normal mucosa with a blood-tinged content, as reported in Dog S-5.

DoGs S-12 and S-9.-Both dogs were killed after forty-four hours, and were apparently in fair condition, Dog S-9 showing a carotid pressure of 100 to 110 mm. of mercury, with almost normal pulsation. There were no visible changes in the loop mucosa, either on gross examination or microscopically. 
DoG S-38.-The dog was killed after forty-eight hours, his condition being "somewhat toxic." "The blood-pressure was practically normal and the pulse regular." "The duodenal loop contains 20 to 30 c.c. of a strawberry-colored thick fluid. The loop shows a diffuse pinkish mucosa, no ecchymoses and no ulcers."

These dogs were killed after from forty-four to forty-eight hours, when in good condition, and no change was found in the mucosa. If the enclosed secretion from the mucosa itself is the active poison, the absorption of which, by the mucosa, causes death, why are the dogs not made more ill? We believe it is because in these individual cases the mucosa was not so severely damaged. If we compare them with Group 1; in which the dogs were allowed to die, and with the group immediately preceding, in which at the end of approximately twenty-four hours the dogs were apparently more toxic, and a definite change in the mucosa was found, we cannot escape the conclusion, from a careful analysis of the cases, that the severity of the toxic symptoms is in direct ratio to the damage done to the mucosa.

In their injection experiments (pp. 301-304) the authors prove beyond question that they have obtained from the contents of the closed loop a substance, which, after sterilization by heat $(60 \mathrm{C}$. for thirty minutes) and filtering through a Gooch or other porcelain filter, is very poisonous, and will cause death in a few hours, if it be injected into the vein, the peritoneum or the subcutis of a dog.

Whipple, Stone and Bernheim find that a similar poison can be extracted from the mucosa (not the loop content) of a non-drained or a drained closed loop, injection of which into dogs produces severe toxic symptoms (pp. 310-311). They argue from this that the substance with which they are dealing is elaborated in the mucosa of the closed loop, and that some unknown force is at work which profoundly alters the activity of the epithelial cells. Yet they emphasize the fact that there is no demonstrable change from the normal. Where do they conceive this toxic substance to arise? They disprove Draper Maury's contention that it is a normal output of the mucosa, which is poisonous unless neutralized with fluids from other portions of the alimentary tract, by showing that duodenal loop fluid, digested with normal intestinal mucosa, loses none of its toxicity (p. 316). With a normally secreting mucous membrane, undergoing no change from the normal, it is difficult to conceive how there is rapidly formed a very toxic material which is directly absorbed from it into the general circulation, with resulting death. It seems inevitable that severe changes take place in the mucosa - they are usually demonstrable - and that the toxic material comes from this alteration in the mucosa. In all cases in which death occurs from the closed loop itself some evidence of damage to the mucosa is described, and the severity of the symptoms runs parallel to the severity of the demonstrable damage. 
A careful study, therefore, of the findings of these authors makes us unwilling to accept their conclusion that a poisonous substance is poured out by a normal mucosa, or elaborated and directly absorbed by the normal cells, which substance produces the toxic symptoms in simple high intestinal obstruction. In discussing the fact that dogs with a simple obstruction may be kept alive at will by simply replacing with normal saline solution the fluid lost in the vomitus, Whipple, Stone and Bernheim say that the benefit derived "is due to dilution and elimination of the toxic material by this means, and the development of a gradually increasing immunity which can be shown to appear in dogs after intravenous injection of the toxic substance" (p. 321). Yet they report conciusive experiments showing that their toxic substance neither exists in the blood of a closed loop dog nor remains for two hours in the blood of a dog that has received a lethal dose intravenously (p. 309). It is difficult to comprehend, then, how saline solution given once a day is capable of washing out from the blood a substance which, within two or three hours, is "fixed by the cells or partly destroyed," and which, if not washed out, will inevitably cause death. If this were possible, one ought to find a cure for organic poisons by a hypodermoclysis, and, similarly, the closed-loop dogs ought to be saved by this means.

In commenting on the claim of Hartwell and Hoguet, ${ }^{20}$ that this action of salt solution is a strong argument against an essential toxemia, and that the loss of water is the important factor, Whipple and his associates say: "One might argue in the same manner that the appearance of sugar in the urine is the cause of diabetes." The analogy is incorrect. Were it possible to alleviate diabetes by the subcutaneous injections of sugar, to the extent that obstruction may be alleviated by injections of saline solution, the analogy would be acceptable, the loss of sugar being the prime factor in one case, and the loss of water in the other.

Moreover, the most potent argument of Hartwell and Hoguet in this connection - a normal starving metabolism when saline is given, and a completely deranged one when it is withheld, as determined by Benedict -is entirely ignored by Whipple, Stone and Bernheim.

It is our contention that the experiments cited by these authors have no bearing on the subject of uncomplicated obstruction. They show, however, that a damaged intestine will produce a substance which is very poisonous if it gain access to the blood. This is exactly the same conclusion we arrived at by a different method of investigation and reasoning.

Still further to test the question, we produced the doubly closed loop in different parts of the bowel on a series of dogs.

The experiments with a doubly occluded loop of intestine, made either by section and inversion of the ends, or by the clamps, need not be detailed because they duplicated in every way the results obtained by Whipple. 
Stone and Bernheim. It is worthy of note, however, that dogs with the double closure in the middle of the jejunum showed the same symptoms and died in the same way as those with a duodenal doubly closed loop. When the jejunal loop became distended with its secretions, and the mucosal circulation was damaged, the animals became sick and ultimately died. The course, however, was less acute. This proved that death is not due to any specific action of the duodenal mucosa, as Whipple, Stone and Bernheim assume. When, however, a double occlusion is produced in the lower ileum, or the cecal region, the animals are not sick, and they may live an indefinite time. Similar results have been obtained by von Baracz. ${ }^{23}$ They are explained by the fact that this part of the intestine secretes very little fluid and consequently there is no distention, no damage to the mucosa, and no absorption of the poisons which higher up result from such a damage.

A series of experiments performed by us with the object of preventing such a damage even in the duodenum gave important results. We believed that if we could minimize the amount of fluids poured out into the duodenal loop and the operative damage to the bowel wall, we could longer retain an intact mucosa, and hence longer delay the fatal outcome. To accomplish this the operation was done in two stages. At the first stage the bowel was sectioned just below the pancreatic duct and the two ends closed by inversion, with as little operative damage as possible. The continuity of the alimentary canal was then reestablished by a lateral anastomosis between the upper duodenal segment and the beginning of the jejunum. In this way there existed a segment of the duodenum below the ducts which was closed at the upper end and drained by continuity directly into the jejunum. The animal was allowed to recover completely from this operation during a period of two weeks. He was then kept without food for four days, and the second stage operation performed. At this time the lower end of the duodenum was sectioned at the site of the entero-enterostomy and the two ends closed, the same care being taken to avoid needless damage to the mucosa in doing this. Thus, there resulted a doubly closed duodenal loop. Following this operation the animals received no food or water by mouth, but were given saline subcutaneously. This was done with the belief that absence of the stimulation from food would materially decrease the secretions in the closed loop, and thereby prevent its overdistention.

In a series of dogs we were able to get a positive result in two in that with a double occlusion of the duodenum without visible damage to the mucosa death did not result as it usually does in the one stage operation with its inevitable damage to the mucosa.

23. Von Baracz: Arch. f. klin. Chir., 1899, lviii, 121. 
Dog 107.-May 1, 1913: An entero-enterostomy was done between the duodenum just below the pancreatic duct and the first part of the jejunum. The bowel was then sectioned and the ends closed by inversion at the proximal end of the loop of duodenum thus formed. Recovery from this operation was completed by May 3, after which he was regularly fed and seemed to be quite normal.

May 12 to 16: All food withheld but water given freely.

May 16: Abdomen again opened, and the distal end of the duodenal loop was sectioned near the anastomosis and the two ends closed by inversion and suture. Thus there was formed a doubly occluded loop of the whole duodenum, while an entero-enterostomy reestablished the intestinal patency. Following this operation he was moderately sick for four or five days. He vomited somewhat. He was given all the water he would drink and no hypodermoclysis. At the end of a week he seemed entirely normal, ate greedily and had no trouble in digesting food. On the seventeenth day after the second operation, the abdomen was again opened. The duodenal loop was found tightly closed at both ends and practically empty. The mucosa was slightly congested, but otherwise quite normal.

Dog 108.- The same procedure was followed as in the previous case. Twentyfive days after the second operation the abdomen was opened and the loop examined. In this case there had been a reestablishment of the lumen from the distal end of the loop into the intestine. This had been possible because after sectioning the bowel, and inverting the two ends at the second operation, they had been fastened in apposition so as to prevent an intussusception. It is not conceivable that this could have resulted under one week, so that the dog lived during this time in good health with a doubly occluded duodenum.

In the whole series of doubly occluded duodena which we did, there was always a direct relation between the severity of the symptoms and the shortness of postoperative life on the one hand, and the amount of mucosal damage on the other.

The two cases cited above we submit as giving final proof to our contention that there is no fatal poison arising from the duodenum when there is no damage to the mucosa.

\section{LOW OBSTRUCTION}

Having demonstrated the causes of death in high intestinal obstruction we next turned our attention to a study of an obstruction lower down. In the following, the obstruction was produced by clamp in lower ileum or at cecum, and treated with small amounts of normal saline solution.

Dog 48.-Weight $13.5 \mathrm{~kg}$. Fed twenty-four hours before operation. Clamp applied just above cecum.

December 12: Vomiting large amount of bile-stained fluid. Given water by mouth and 200 c.c. subcutaneously. Condition good.

December 13: Drank water greedily; 200 c.c. saline subcutaneously. Condition good. Temperature, 40. Pulse, 120. Vomiting somewhat.

December 14: Same.

December 15: Condition not so good. Acts sick. Pulse 145.

December 16: Very sick. Vomitus excessive. Bright red in color. Fecal in character and very foul. Pulse 180.

December 17: Died during night. Lived five and one-half days.

Autopsy.-Obstruction complete. Small abscess around clamp. No peritonitis. Very intense congestion throughout peritoneum. Kidneys and liver intensely congested. 
Alimentary Tract: Stomach not distended, but mucosa somewhat congested. Duodenum the same. The entire ileum is greatly distended, wall thin, mucosa intensely congested. In lower part hemorrhagic areas are present, and in spots superficial areas of necrosis exist.

Danage to mucosa caused death.

Dog 50.-Weight $5 \mathrm{~kg}$. Fed few hours before operation. Clamp applied just above cecum.

The postoperative condition exactly parallel to that of Dog 48 . Remained in excellent condition for three days; then began to sicken and died after five and one-half days. He received from 150 to 210 c.c. water subcutaneously each day and drank in addition. Vomited every day.

Autopsy.-Obstruction complete. No peritonitis. Same changes found as in Dog 48. The ileum above the clamp was enormously distended and black in color. No actual necrosis seen. Kidneys and liver markedly congested.

Doa 52.-Fed twenty-four hours before operation. Weight $12 \mathrm{~kg}$. Clamp applied just above cecum.

Postoperative behavior as in previous cases, except that he remained well for nine days, after which he grew sick. Received 200 c.c. of saline subcutaneously each day. Vomiting much less than in other cases.

Killed with ether on tenth day while in apparent fair condition.

Autopsy.-Obstruction complete. No pertitonitis. Upper bowel empty. Lower ileum much congested, markedly distended and containing a quantity of foul-smelling liquid, fecal matter. There was a marked peristalsis still present, and the fuid contents of the bowel could be seen continuously forced downward to the site of the obstruction. There was no marked evidence of the damage to the intestinal wall seen in the other cases. The liver showed some congestion, but otherwise the organs appeared normal. ${ }^{24}$

Cultures from the peritoneum, femoral blood, spleen and liver all proved negative, both anaerobically and aerobically.

This type of experiment was done six times, and the results accorded in every way with the three here described. Length of life exactly paralleled the lack of injury to the intestine as it had done in the high obstruction.

In the following low obstruction was treated with excess of saline subcutaneously:

Dog 85.-Clamp applied $62 \mathrm{~cm}$. above the cecum. Normal saline, 400 c.c., was given subcutaneously at the end of the operation. This was repeated the next day, but in spite of it the dog only lived forty-six hours.

Autopsy.-No peritonitis. Obstruction complete. The bowel below the clamp is collapsed and empty. Above the clamp the bowel is dilated all the way to the stomach, being four or five times the normal diameter for a distance of $150 \mathrm{~cm}$. This intestine shows very marked vascular changes throughout this length, as instanced by the presence of deep ecchymoses which involve all the coats except the peritoneal, through which, however, they are readily seen.

These changes are most marked on the convex border of the intestine, the surface at which the circulation would be naturally most disturbed by the excessive distention. There are no actual ulcers or necrotic areas seen in the mucosa.

Microscopical Examination.-The intestinal mucosa in the above areas is practically destroyed. There is edema throughout the entire wall of the bowel.

24. The length of life, and the absence of symptoms for such a long period, was due to lack of excessive vomiting and lack of damage to the intestine. 
Between all the layers is a beginning purulent exudate with hemorrhages. These changes are probably of microbic origin.

DoG 86.-Clamp applied $40 \mathrm{~cm}$. above the ceeum. Dog remained perfectly well for three days. On the fourth day he began to act sick, and on the fifth day was greatly prostrated though still able to walk around the laboratory. During the five days the total output of urine and vomitus was 2,030 c.c., which was replaced by the administration of 2,050 c.c. of normal saline solution. The dog was killed with ether and the autopsy immediately done.

Autopsy-No peritonitis. The clamp was tight and produced a complete obstruction. The bowel above the clamp was moderately distended for a distance of $50 \mathrm{~cm}$., and shows no gross changes on peritoneal surface, except for congestion immediately above the clamp.

When the bowel is opened there are seen many scattered small areas where the mucosa is much damaged, in places showing a beginning necrosis. The content of the bowel is ordinary fluid fecal material.

Microscopical Examination.-There is an almost complete necrotic destruction of the mucosa at the points mentioned above. The entire thickness of the bowel wall is edematous and shows signs of acute exudative inflammation.

Kidneys: Acute parenchymatous inflammation is present.

Liver: Granular and lipoid degenerative changes are present.

Dog 88.-The clamp was applied $100 \mathrm{~cm}$. above the cecum. This animal lived ten days, having remained in excellent condition for eight days. The vomiting was not so excessive as in the high obstruction, but was fecal in character and exceedingly offensive after the third or fourth day. The total output of urine and vonitus in ten days was 2,930 c.c., and the saline injections amounted to 3,900 c.c.

Autopsy.-There was no peritonitis. The obstruction was complete, the bowel below the clamp being collapsed and empty. Above the clamp the intestine was distended and filled with foul-smelling fluid feces. There was a slight purplish discoloration of the bowel for about $35 \mathrm{~cm}$. above the obstruction. The mucosa appeared somewhat edematous, but there was no evidence of uleeration or necrosis.

Microscopical Examination.-The intestine shows congestion and edema. There are areas in which some necrosis is present, with exfoliation of the mucosal cells. No pyogenic infiltration is seen.

Liver shows only congestion.

Kidney shows congestion and some parenchymatous degeneration.

DoG 87.-The clamp was applied in the lower ileum. This animal lived in apparent perfect health for eighteen days, when he was killed. The total output of urine and vomitus was 3,950 c.c. and the injections of normal saline totaled 6,600 c.e.

It will be noted that the output of fluids is far less than in the high obstructions, and hence the quantities of saline injected may be reduced.

Autopsy.-There was no peritonitis. The obstruction was complete, the bowel below being empty and collapsed. The bowel above the clamp was moderately distended, but there was an absence of the discoloration, hemorrhages and other evidences of tissue damage seen in the other cases. On opening the intestine the mucosa appeared absolutely normal throughout, except for one small area $5 \mathrm{~cm}$. in diameter, about $20 \mathrm{~cm}$. above the clamp, where there was an ecchymosis.

Microscopical Examination.-The intestine shows only a slight congestion. There is an absence of the lesions found in the animals which died at an early date.

The kidneys and liver are entirely normal.

The study of low obstruction gives, therefore, results exactly like those found in the high obstruction. Dogs may be kept alive indefinitely by the injection of an excess of normal saline solution, if the intestinal 
wall remains undamaged. Such injections, however, will not save life where there exist lesions in the mucosa which destroy the natural protection against the absorption of bacterial and other poisons from the lumen of the bowel.

It may be asked what actual evidence has been found that poisons enter the system even under these conditions. The evidence is indirect and inferential. It is plain that so long as the mucosa remains intact, and desiccation of the tissues is prevented, there is no absorption of poisons because the animals remain in perfect health. This does not mean that the stagnated intestinal contents would not prove poisonous if they could enter the blood. On the contrary, they are poisonous even after sterilization by boiling and filtering, as many investigators have shown. In every instance, however, in which serious symptoms of sickness develop and ultimately the animal dies, a damaged mucosa is found at autopsy. Study of this lesion shows it to be a destructive one. The mucosa is more or less destroyed and all the evidence is present that there is a bacterial inflammation in the intestinal wall. The severity of the symptoms varies directly and the length of life inversely with the extent of this damage. It is just as certain an inference that some poison is absorbed under these circumstances as any other of the many infective inflammatory lesions which we recognize as being the source of a toxemia, even though a bacteriemia is absent.

There are two points to be explained in comparing the high and low obstruction. First, why do the animals with the latter vomit a less quantity? Second, why cannot all the dogs with a low obstruction be kept alive by the administration of saline solution?

The vomitus is reduced in the low obstruction because there is a long surface of intestine through which absorption takes place. Similarly the dogs are less desiccated because the water content of the bile, gastric and intestinal juices reenter the body. On the other hand, there is practically no absorbing surface available for this purpose in the high obstructions, and the distance backward into the stomach being short, the latter organ rapidly fills and vomiting is imperative and almost incessant.

The explanation of the inability to save life in low obstruction is found in the mechanical conditions which exist. The small intestine above the obstruction becomes distended, and following this, kinking and tension on the mesentery develops. In this way there are areas in which severe circulatory disturbance is present, resulting in the very changes which we have found will cause death and which are uninfluenced by the administration of saline subcutaneously.

The results of our investigations of intestinal obstructions may be summarized as follows: 
1. There are two factors at work in producing the symptoms and causing death in this condition.

First, the loss of water from the tissues, due to the excessive drain into the bowel in response to the irritation set up by the retained secretions. This water may be replaced by subeutaneous injection of normal saline solution, and the symptoms caused are thus entirely controlled, with a saving of life.

Second, the entrance into the circulation of poisonous materials, which occurs only when the mucosa of the bowel is damaged. This damage results largely from the trauma inflicted by the overdistention acting on the circulation, but possibly also by the chemical action of the digestive ferments stagnated above the obstruction. Such a damage having resulted, there occurs a bacterial invasion into the bowel wall with a death of tissue cells (which is invariably demonstrable by microscopical examination), and in this process the poisonous substances are elaborated. The action of these poisons is apparently not influenced by the administration of saline subcutaneously.

The absorption of a poison from any source whatsoever, so long as the mucosa remains intact, is not a factor.

2. The development of a bacteriemia as a cause of death is excluded.

\section{CLINICAL APPLICATION}

It is not always safe to transfer the findings of experimental work to clinical practice, and as yet we have had no extended opportunity to apply the teaching of our investigations to the bedside. There are certain applications, however, which seem justified. It has always been a matter of speculation why high intestinal obstruction in man is so much more acute than low obstruction. The explanation is found in the fact that water absorption is entirely stopped in the first, and in addition, enormous amounts of water are thrown out in the vomitus almost as soon as the obstruction occurs. A rapid desiccation takes place, and with it a severely damaged metabolism, as shown by the deranged urine output. These conditions obtain much more gradually when the obstruction is low in the bowel. Another factor is also found in the sudden enormous duodenal and gastric distention which mechanically damages the mucosa.

It is a familiar observation that a chronic obstruction may take place in the bowel and progress until the opening is only pin-point in size, yet no serious symptoms arise, even though there may be for many days cessation of fecal passage from the bowels. When, however, a complete closure supervenes, there arises immediate evidence of a severe condition. The well-known symptoms of acute intestinal obstruction are manifest. The explanation of this is found in the fact that so long 
as gas can escape through the constriction, there is no distention of the intestine, and hence no damage to the intestinal wall, and no absorption of poisonous materials. 'The stoppage of gas, however, is immediately followed by both these conditions, and unless promptly relieved will result fatally. The practical application of the principles elaborated by the experimental work follows two lines. First, the water extracted from the tissues by the enormous outpouring into the bowel must be replaced. This can easily be done by means of a continuous hypodermoclysis administered under the skin in the pectoral region by use of needles of the ordinary hypodermic caliber, but longer. In this way the fluid is absorbed almost as rapidly as it enters, 1 or 2 liters being given without withdrawing the needles. The absorption will continue until the normal water content of the tissues is reestablished. Since, however, this has no influence on the symptoms resulting from a damaged intestinal wall, it is imperative to relieve the obstruction surgically as early as it is discovered. A second point of practical importance is derived from our experiments, that is, an answer to the question as to the advisability of opening the bowel, and either temporarily or permanently draining off the contents. Whenever there has resulted from the obstruction any considerable damage to the kowel wall above the constricted point, by reason of distention and circulatory changes, there is danger of serious symptoms arising from the absorption of materials resulting from these changes. Therefore, in the presence of such changes, the more rapid emptying of the bowel through an enterostomy than through the normal path, after relieving the obstruction, may be a wise thing to do. Whether the drainage of the intestine shall be made to continue after primarily emptying as much as may be possible of the distended bowel depends on the extent of the damage done. If this is great in amount, it may be advisable to establish an enterostomy, because there will be some farther accumulation of the poisons which will be absorbed unless there is a free exit for them. Such an enterostomy will be necessary if the contents of the bowel above the obstruction are blood-tinged, demonstrating a damage to the bowel wall. If it is simply fluid feces, the rapidly returning peristalsis, after the obstruction is released, will force the contents onward, and there will be no danger of poisonous absorption when once it gets into normal bowel below the obstruction, because the mucosa here possesses a defense against such absorption.

We desire to express our thanks to Drs. Elser, Benedict, Ewing and Lusk of the Cornell University Medical College who gave us many valuable suggestions and material aid in parts of the work here presented. Street.

27 East Sixty-Third Street-40 East Forty-First Street-55 East Sixty-First 